\title{
Microwave Enthrakometric Labs-On-A-Chip and On-Chip Enthrakometric Catalymetry: From Non-Conventional Chemotronics Towards Microwave-Assisted Chemosensors
}

\author{
Oleg V. Gradov *(i) and Margaret A. Gradova $(1)$ \\ N.N. Semenov Federal Research Center of Chemical Physics, Russian Academy of Sciences, Kosygin Street, 4, \\ Moscow 119991, Russia; gradov@chph.ras.ru \\ * Correspondence: o.v.gradov@gmail.com
}

Received: 30 August 2019; Accepted: 15 October 2019; Published: 17 October 2019

check for updates

\begin{abstract}
A unique chemical analytical approach is proposed based on the integration of chemical radiophysics with electrochemistry at the catalytically-active surface. This approach includes integration of: radiofrequency modulation polarography with platinum electrodes, applied as film enthrakometers for microwave measurements; microwave thermal analysis performed on enthrakometers as bolometric sensors; catalytic measurements, including registration of chemical self-oscillations on the surface of a platinum enthrakometer as the chemosensor; measurements on the Pt chemosensor implemented as an electrochemical chip with the enthrakometer walls acting as the chip walls; chemotron measurements and data processing in real time on the surface of the enthrakometric chip; microwave electron paramagnetic resonance (EPR) measurements using an enthrakometer both as a substrate and a microwave power meter; microwave acceleration of chemical reactions and microwave catalysis on the Pt surface; chemical generation of radio- and microwaves, and microwave spin catalysis; and magnetic isotope measurements on the enthrakometric chip. The above approach allows one to perform multiparametric physical and electrochemical sensing on a single active enthrakometric surface, combining the properties of the selective electrochemical sensor and an additive physical detector.
\end{abstract}

Keywords: enthrakometer; bolometric sensor; microwave electrochemistry; chemical radiophysics; modulation polarography; catalymetry; on-chip chemometrics; microwave chemotronics; chemical oscillations; spintronics and spin chemistry

\section{What is an Enthrakometer?}

It is well known that in order to measure microwave power (primarily, passing through) in waveguides using wattmeters, the "absorbing wall" method employs enthrakometers-thermosensitive film elements that are designed, in most systems, on the basis of a resistive platinum layer applied to a glass carrier, placed on the side wall of the waveguide with the sensor element in the center. This allows them to selectively absorb a small percentage of the power transferred to the selective load (as the resistance of the enthrakometer as a measuring structure is much lower than the active component of the load resistance) when the enthrakometer, a resistive element with thermal losses, is included into a circuit of a pre-balanced direct current (DC) bridge. The DC bridge becomes unbalanced when the film absorbs power during heating (relative to a similar element of thermal compensation, localized on the outer part of the waveguide and included in the bridge circuit), which provides the power indication.

Some authors define enthrakometer as the waveguide wall bolometer, which correlates with its metrological role in the temperature-mediated (according to the physical principle) "absorbing wall" 
method. In other works, the term "enthrakometer" is interpreted too broadly, meaning both film bolometers with Te-Zn and other sensors, and classical platinum Collard enthrakometers. (The first platinum enthrakometer as a measuring system was proposed by J. Collard in 1946 as an alternative to the contemporary standard of an electroscope based on the gold sheets [1] that measured power [2], along with his other invention, the complex for measuring voltage in the centimeter range [3] with the help of an electroscope based on the gold sheets). Further parametric improvement of enthrakometers by commercial companies resulted in closing access to the information on the materials and methods of thin-film technology applicable in the manufacture of commercial sensor types [4] (cited in [5]). Therefore, when discussing enthrakometric methods, in most cases it is possible to confine ourselves to classical platinum Collard systems described in the works cited above.

It is also known that the surface of platinum is a classic material for polarography: the Geirovsky electrolyzer contains both a liquid metal mercury anode and a platinum wire. In oscillographic polarography, stationary platinum electrodes (in addition to $\mathrm{Hg}$ ) are used as the indicator electrodes in the studies of the structure of compounds and adsorption phenomena. When using film mercury electrodes, platinum is taken as an inert substrate (in cases where it is undesirable to use a carbonaceous substance such as graphite or glassy carbon, or silver is inadmissible), on which a micron/decamicron $\mathrm{Hg}$ layer is applied. In inversion techniques with electrode measurements, in a number of crucially important cases, electrodes with a platinum substrate display the lowest substrate dissolution effect (hence, the lowest probability of intermetallide formation during electrolysis, which increases metal concentration in dilute solutions by two or three orders of magnitude). As a rule, platinum is selected when it is necessary to optimize the electrode material by the criteria of solubility in mercury and its wettability, and also chemical inertness in a given medium (again, to reduce the effects of the formation of intermetallic compounds with mercury or a detected metal). In polarographic methods, an alternative to the "mercury bottom" is inert Pt-electrodes, which are used as effective auxiliary electrodes with a highly developed active surface.

An alternative to the amalgam electrodes at high current densities is oxidation-reduction (so-called redox) electrodes, including platinum electrodes in a solution of Fe (II) and Fe (III) salts. When in the course of the experiment it is unacceptable to increase the thickness of the diffusion layer, and is undesirable to reduce the limiting current, a platinum rotating microdischarge electrode is preferable, and such microelectrodes are often used in oxidative polarography (in reducing polarography, it results in precipitation on the metal surface). Platinum electrodes in aqueous solutions are non-polarizable by definition; therefore, it is not possible to arbitrarily change the voltage without creating significant currents or to construct an analytic polarogram/voltammogram because of the catalytic (electrocatalytic) properties of platinum. This rather incomplete list of applications of platinum microelectrodes in polarography, according to the "PLAT_SPECTROPOLAR" database [6], indicates that enthrakometry in the microwave range can be combined with some polarographic techniques.

\section{Microwave Enthrakometry in its Relation to Polarography}

It is necessary to clearly understand what information can be extracted from the data of microwave enthrakometry in its relation to polarography. The fact is that there are no precedents when analytical polarography was implemented directly in the microwave range. Quite often, a superficial citing of the works on microwave sample preparation during polarography leads to a linguistic incident $[7,8]$ because, in fact, microwave radiation does not participate in the process of polarography, and even at the sample preparation stage the microwave irradiation is nothing more than an alternative to conventional heat treatment with no consideration of the wavelengths [9]. Polarography with the so-called "fast scanning" operates classically in a range from $\mathrm{kHz}$ to tens of $\mathrm{MHz}$ [10], while modulation polarography operates in a range of several megahertz [11]. In the novel method of drop voltammetry with synchronous processing by the electromagnetic field, the frequency used is $55 \mathrm{MHz}$ [12]. Methods of electrochemical radiofrequency purification [13], as a rule, also do not work in the microwave region. Analytics at the basic and second harmonics [14-18] do not change the physical nature of 
the process. From the metrology standpoint, the accuracy of polarographic measurements does not require microwave frequency, as the necessary improvements can be achieved without the frequency increase [19-22].

Therefore, introduction of microwave enthrakometry into polarography should be associated not with the need of the measurement accuracy, but with the additional effects introduced into the system at the same time. As stated above, there are several precedents for the use of microwave sample preparation in polarography (not in situ). However, in radiofrequency polarography (at lower frequencies than microwave bands), some studies established the temperature dependence of the lengths of polarographic waves [23]. Other studies that combined low-temperature oxidation with polarography have been widely cited until the last decade [24]. Combination of these data with generalizations published recently in the Journal of Thermal Analysis and Calorimetry [25] allows us to see the prospect of working with microwave frequencies in polarography as an activator of chemical processes. The extensive data on the microwave activation of electrochemical systems [26-28] no longer allows us to explain the results potentially observed under the given conditions purely by the thermal effects. Accordingly, if a new method for controlling excitation parameters is implemented, a new data pool will be obtained that can shed light on the processes leading to the activation effects.

\section{From MW-Polarography to "Autowave" and "Self-Oscillating"}

On the other hand, the chemical effects of these processes are of fundamental interest to microwave chemistry, and catalysis in microwave chemistry, especially electrocatalysis, in most nonstandard systems remains a largely unexplored region. Considering the high catalytic capacity of platinum described above, it is expedient to conduct studies taking into account the surface of the enthrakometer and its catalytic properties. Considering the growing interest in the catalysis on platinum surfaces, including the most exotic forms [29-35] and excluding the well-known examples [36,37], it becomes possible to use platinum enthrakometers to study the formation of intermetallides, the electrochemical synthesis of organometallic compounds, adducts, etc. Considering the emergence of self-oscillations in a number of reactions in the gaseous phase on the platinum surface [38-43], the use of platinum enthrakometers under gas flow in a multiphase catalytic cell allows one to speak about an "autowave" or "self-oscillating" catalymetry on the surface of an enthrakometer under microwave irradiation. This provides new parameters for complementary measurements and allows one to formulate an understanding of the active medium under microwave pumping as an activated source of nonstandard, nonequilibrium $[44,45]$ surface catalytic processes in which the electrophysical characteristics of the substrate gain significance [46-48].

To solve these fundamental problems it is necessary to develop a system integrating the enthrakometer, polarographic modules, a microwave source, a set of modules for analyzing the microwave signal parameters, a subsystem for sample preparation and injection/introduction of the analyte and a gas medium inlet, controllers for sealed valves, etc. We propose abandoning the outdated modular approach and to hybridize on a single platform (in a single "lab-on-a-chip") at least half of the above mentioned components.

\section{Microwave On-Chip Systems: From Physics to Chemometrics}

In regards to microwave research systems on a chip, we primarily have devices for microwave photonics in mind, including phase shifters [49,50], modulation and frequency discrimination systems on photonic chips [51,52], filters and phase shifters based on stimulated Brillouin scattering [53-55], and microwave frequency synthesizers based on the Brillouin oscillators on a chip [56]. In other cases, we mean the on-chip electron manipulation systems [57,58] (including the systems for manipulating single electron spins [59], with earlier analogues implemented by tunneling microscopy and micromanipulation [60-62]), and on-chip atomic clocks [63].

At first glance, there is a significant difference between microwave chips and on-chip devices, on the one hand, and chemical labs-on-a-chip, on the other. However, this is not quite true for several reasons. 
Firstly, the degree of integration of on-chip microwave systems (microwave electro-optomechanical devices [64], combining fermion communications, microwave cavity resonators and quantum dots [65], and similar chips) is increasing so that it allows one to control and modulate a number of parameters on a chip, including those related to the analytical signal outside the microwave band.

Secondly, new microwave chips with a chemometric orientation have appeared that can be used in studying the physicochemical properties of the substance/analyte and the processes in it-radio frequency spectrum analyzers $(640 \mathrm{~Gb} / \mathrm{s}$ - microwave band) on photonic chips [66], radiometers in the system-on-chip (SoC) format [67], photonic devices with optical delay and signal processing on complementary metal-oxide-semiconductors (CMOS) [68] (note how widely CMOS matrices are used as detectors in standard labs-on-a-chip [69-71], including those hybridizing optical and electrochemical methods of analysis [72], in addition to CMOS controllers and CMOS-based power supplies for analytical microfluidic labs-on-a-chip [73,74]).

Thirdly, there are "quantum-mechanical labs-on-a-chip" [75], based on the same fundamental principles as on-chip microwave photonic devices. Fourthly, channel addressability, typical of microwave electronics, is used in microbiological microwave labs-on-a-chip, in particular, with wireless selectively addressable heating during sterilization on a chip and in a centrifuged microfluidics [76]. This is the reason for bringing microwave microelectronics and microfluidics closer in the form of creating multifactor chips or labs-on-a-chip that synchronously perform the functions of physico-chemical analysis and microwave preprocessing with multiparametric correlation control of the former and the latter by electrophysical/electrochemical methods.

\section{From On-Chip Voltammetry to On-Chip Microwave Electrochemistry}

Voltammetric labs-on-a-chip (which are the closest to standard polarography, especially in the case of "stripping voltammetric detection" [77]), used in analytical or bioanalytical applications [78,79], usually for detecting the metal concentration in a sample (in the case of biological samples - either as microelements or as toxins) [80-83], are a classic example of implementing electrochemical analytics with metal electrodes on a microfluidic/microanalytical chip (often fabricated by the microelectronic methods using the techniques of isotropic or anisotropic etching, photolithography or electron beam lithography, etc.). Therefore, even if the rational possibility of implementing a microwave source on the same chip in the form of a resonator [84] is discounted, the microminiaturization of electroanalytical and microwave procedures on a single chip obtained using microelectronic techniques, can obviously be achieved. In this case, the only conceptual issue is not the technical implementation, but the value of the electrochemical data that is obtained in the microwave band. As there is no polarography in the microwave band, as it was pointed out in the previous section, a broader search concept should be used-microwave electrochemistry.

The first principles of the latter allow one to predict or interpret the data from on-chip enthrakometric catalymetry and on-chip enthrakometric oscilloscopic (using stroboscopic microwave oscilloscopes) microanalytics in general. Wikipedia states (and, unfortunately, this statement is frequently cited in publications) that microwave (microwave-stimulated) electrochemistry was established only in 1998, when F. Marken and Richard G. Compton integrated platinum wire into the cavity of the microwave resonator in an electrochemical cell [85]. This is partially true, as similar work was carried out before, while the first English-language papers really became available in this period. For example, microwave photoelectrochemistry or electro-photochemistry go back to 1993 [86], and the review of 1999 on this topic referenced mainly links from the 1980-1990s to 1998 [87]. Microwave electrochemistry is essentially capable of operating with locally superheated liquids-electrolytes of different phase composition (two-phase and multiphase systems) and heterogeneous, partially structured soft-matter media such as micellar systems [88,89].

The implementation of microwave electrochemistry on a chip is associated with the microminiaturization of its electrode part (without exceeding the permissible size for the microwave bands). In this connection, the development of micrometer-sized electrodes for microwave 
electrochemistry is worth studying [90]. Undoubtedly, due to the heterogeneity of the electrophysical phenomena and the physicochemical mechanisms in different microwave subbands, this can only be considered as a pioneering work. However, Hbhhjh this research provided proofs for two important principles. Firstly, being essentially a physical sensor in catalymetry, such an electrode as an enthrakometer is a potential activator at the stage of studying microwave-chemical kinetics (catalyst, electrocatalyst), that is, in one electrode it can combine a chemically active and physically-passive (receiving and detecting) function on a single chip. Secondly, if we consider electrode matrices as antennas, then a certain compatibility with a wavelength is required.

Moreover, if we use an electrode-enthrakometer as a power sensor that is not synchronized with the radioelectronic measuring system (which follows from the physical problem), then this is not obligatory. Hence, it is possible to implement sources and detectors for wavelength bands on a chip that do not correlate rigidly with the chip size. This possibility depends on whether it is planned to investigate not only thermal, but also selective (radio-frequency, magnetic resonance, etc.) effects during the experiment.

\section{Towards Combined Electron Spin Resonance and Polarographic Chip/Pt-Electrode Enthrakometer Measurements, including MW-Field Electrophoresis}

In connection with the above remark, one should point out the experience of combining measurements on polarographic electrodes with EPR methods in the microwave region (L-band, 1.2 GHz) in physiological and biochemical experiments [91], as well as the precedents of electron spin resonance monitoring of radical generation in electrochemical aqueous systems [92]. In the 1980s, for such measurements, specialized fittings with thermal regulation were developed [93] in full agreement with the prevalent ideology of the empirical separation of thermal and nonthermal effects on a chip when electrocatalytic enthrakometers are used. It should be noted that the Pt-containing electrode was used in [91]: $\mathrm{PtO}_{2}$ is the Adams catalyst used for reduction and hydrogenolysis in organic synthesis (as platinum dioxide hydrate). The thermal effects of the boiling type and the appearance of jets in microwave voltammetry [94] are purely thermal, and therefore do not fall within the specific impact of microwave subbands.

Therefore, the so-called "microwave enhanced electroanalysis", carried out in particular on Pt-electrodes [95], can be performed on them as on enthrakometers in the range of thermal effects, only non-selectively to the effect of specific bands/wavelengths. Differential measurement methods with reference to the wavelength and thermal effect are recommended to be carried out using electrodes of different heat capacity.

The so-called generator-collector voltammetry at paired electrode junctions [96] can, with modification and certain additions, be implemented within this task. In this connection, it is worth considering on-chip two-electrode capillary electrophoresis with a platinum wire as a pseudo-reference electrode [97], as capillary electrophoresis is used as a tool for microwave-activated electrochemical detection [98], but at the same time, microwave-activated electrophoresis has not yet been implemented on a chip.

\section{On the Way to the Multilayer Microfluidic Polarographic Catalymetry}

Polarographic catalymetry is an analytical method where parallel to the measurements, the analyte precipitates on the platinum electrode, changing the detector parameters. To eliminate this problem, chemists often use rotating platinum electrodes and a limitation on the analysis polarity (using them only in oxidation schemes, as, in the reducing conditions, the sediment on the electrode surface is formed). In the case of using microfluidic technology that combines the properties of an analytical sensor and a microreactor, it is possible to treat sedimentation not only as a problem but also as an opportunity to introduce an adaptive manufacturing process in which the properties of the enthrakometer surface exposed to microwave radiation are controllably modified during its operation on a chip. Moreover, it is possible to create rotational sensor systems (similar to 
centrifugated and so-called "spin-coating-assisted" planar microfluidics) based on the rotation modes of the Pt-electrode-bearing platform in the microwave device. It is well known that platinum is widely used as a sublayer/underlayer for film deposition [99]. Sedimentation and growth of other metals on the platinum electrode are controlled by electrochemical methods, in particular, by cyclic voltammetry $[100,101]$, synchronously with methods based on non-electrochemical principles [102]. As a consequence, it is possible to combine electrochemical catalymetry on platinum electrodes and microwave enthrakometric catalymetry in a single device.

Due to inertness and the corresponding activation barrier, magnetron sputtering on platinum is less effective for a number of structured films with a perovskite-like structure than for other inert substrates/carriers $\left(300^{\circ} \mathrm{C}\right.$ for Au versus $650{ }^{\circ} \mathrm{C}$ for $\mathrm{Pt}$ [103]). This is confirmed by the morphology of the films and the results of X-ray diffractometry and X-ray photoelectron spectroscopy (XPS). However, the production of piezoelectric films based on similar technologies on platinum (and platinum-coated silica) substrates $[103,104]$, in a multilayer technique allowing one to obtain capacitors with a very high dielectric constant, makes it possible to introduce new descriptors into the analysis performed by the modified enthrakometer in situ. Its surface properties are controllably changed in the course of the ongoing analysis. The change in surface-coupled properties alters the nature of the reactivity of the enthrakometer. The above compounds with a perovskite structure obtained by the magnetron sputtering methods [103] which can be controllably crystallized in a microwave field [104], are used in the design of triboelectric photodetectors (including hybrid ones with other materials) [105-108], gas sensors [109-112], and non-enzymatic sensors for a number of important biochemical agents (glucose, peroxide) $[113,114]$, etc.

Despite the difference in the methods of production and technical processes in specific cases, it is possible to design an enthrakometric sensor with a complex of active properties in electrochemical processes at the microwave field. In this case, we do not consider non-chemometric applications (such as the design of mechanoelectrical transducers or acoustic sensors), but it is yet enough to confirm the possibility of on-chip implementation, in a microwave field, of multifactor chemical microanalytical techniques that require chemometric approaches to data analysis.

\section{From On-Chip Microwave Chemical Measurements to Real-Time Microwave Analog Signal Processing/Analog Computations on the Enthrakometric Chip}

Obviously, the development of chemometrically-interpreted techniques, in terms of microminiaturization and achieving a high degree of integration, requires as many operations on the chip as possible, preferably with delegating the functions, previously performed by the autonomous units, to the analytical part of the chip, at least in the analog form. In the case of microwave catalymetry, the operation of the digital element base may turn out (and it does) unstable, so the rationality of the transfer of its functions to the analog part of the chip increases. It is not noise immunity that is problematic, but the fact that a part of the functions usually stably implemented by the digital logic at the digital signal processing stage can be performed in the microwave field by the sensor itself as a result of the physical and chemical processes occurring in it.

This is not microwave computing in the standard form [115-119] (although the elements of the latter can be implemented on the chip), but rather an extended analogue of the popular R-ASP approach ("real-time analog signal processing", also called microwave analog signal processing MASP) [120-124], differing from it in that the microwave treatment operation on the chip is performed by a microwave-activated chemical medium, similar to the methods of computing and pattern recognition based on chemical self-oscillations in photoactivated active media [125]. Self-oscillations in catalytic regimes are also reproduced on the platinum surface of a thin-film enthrakometer [126-128], therefore implementation of the analog signal processing on an active Pt medium is theoretically possible. 


\section{From Oscillating On-Chip Computations to Microwave Chemotronics}

The fact that active media performing operations based on electrochemical and catalytic principles are present among the microwave detectors demonstrates that it is possible to consider microfluidic chips using such detectors as analog chemotronic devices-a kind of hybrid chemotronic circuits. A real-time analog signal processing using chemotrons is possible: nonlinear function converters, integrators, relays, rectifiers, analog memory elements, amplifiers, peripheral output devices based on "chemotrons" are well known [129-135]. By the way, the founder of chemotronics, A.N. Frumkin, began his work specifically with platinum electrodes [136-139] and methods implemented using rotating electrodes [140], so the implementation of a number of methods developed by A.N. Frumkin, on platinum enthrakometers can be considered, to a certain extent, a continuation of the classical electrochemical methods of Frumkin's school of electrochemistry.

At the same time, a significant drawback of the standard approaches of chemotronics is the low operation speed: the ions that are the charge carriers in chemotronics are $10^{4}-10^{6}$ times less mobile than the charge carriers in semiconductor electronics. As a result, the boundary frequency range for the hemotronic devices is only $10^{-7}-1 \mathrm{kHz}$. Overcoming this problem lies within the competence of the electrochemical or material science approach to the analysis of processes and deposited substances on the electrode, the enthrakometer, which implies the existence of two approaches to overcoming the problem, the "chemical" one (based on the selection of a suitable in situ modification of the electrode surface) and the "physical" one (based on the physical mechanisms of ion acceleration in the microwave field within the electrochemical active medium).

The substrate part of the problem consists of the fact that at room temperature the ion charge transfer in solids is insignificant with the specific conductivity $\sigma<10^{-10}-10^{-12} \Omega^{-1} \cdot \mathrm{cm}^{-1}$ [141]. In this respect, the only "substrate" solution is the transition to the media with greater electrical conductivity, such as superionic conductors, whose electrical conductivity can be $10^{-1} \Omega^{-1} \cdot \mathrm{cm}^{-1}$. It was pointed out that compounds with a perovskite structure obtained by magnetron sputtering, which are controllably crystallizable in a microwave field $[103,104]$, may be of interest for creating chemometric chemotron microwave chips (MW-chemotronic chips).

\section{Microwave-Accelerated Charge Drift in Materials Science and Elionics}

It should be noted that anti-perovskites, such as LiRAPs (lithium rich anti-perovskites), are superionic conductors [142-144], which belong to the perovskite-like type [145] (crystalline structure of antiperovskites is isomorphic to the perovskite structure, with the exception of the rearrangement of anions and cations in the crystal lattice). In this case, Pt-containing carbides of the antiperovskite type [146], being transition metal carbides used for producing electrodes with electrocatalytic properties [147], can be obtained by the microwave synthesis method [148]. The same is true not only for platinum compounds that are capable of melting in conditions of microwave processing at standard industrial technological frequencies, but also for the most refractory transition metal, tungsten [149], often used in electrochemistry for the assembly of metal oxide electrodes for redox potential measurements.

Taking into account the similarity of the methods for synthesizing platinum and platinum-doped materials with increased conductivity, including perovskite-type superconductors [150], it should be noted that non-precious metal carbides with Pt additives behave electrochemically as noble metals for the corresponding reactions, such as oxidation of hydrogen, carbon monoxide (capable of reducing $\mathrm{Pt}$ salts at solutions and increasing its chemical activity under microwave heating) and alcohols, as well as oxygen reduction [147]. In this connection, it can be assumed that thermal diffusion doping of the resulting superionic material with platinum can be achieved in situ directly with its microwave-induced formation on a platinum probe-enthrakometer that supplies energy (in fact, the power measured by it, as the integral of the instantaneous power for a period of time is equal to the total transferred energy during this time) to the microwave synthesis zone. This is also metrologically justified from 
the point of view of chemotronics [151], as numerous works using platinum as an electrode for wide-range/multifrequency measurements on superionic conductors support this view [152].

The physical part of the problem lies in the fact that the frequency dependence of the conductivity of solid electrolytes, superionic conductors, is determined by factors different in nature, associated with the mobility of ions, electrons, polarization phenomena and related processes. The reverse logic allows one to conclude that the microwave field can enhance the mobility of the charge carriers, including ions, thereby expanding the frequency range in which chemotronics can be used up to the high-frequency boundary determined by the possibilities of an accelerating source with the correction for decay/dissipation. If we consider the phenomenon of the ion intercalation (alloying/doping) in the microwave field (and under the action of this field), it can be compared with the technological processes of surface implantation.

However, "traditional methods of implantation are based on the ion acceleration in a vacuum and near-electrode layers of a glow discharge" [153] at low pressure, while at the same time at "atmospheric pressures convenient for electrochemical experiments to transmit energy exceeding thermal energy to surface ions by accelerating in a constant electric field is almost impossible" [153]. An alternative to this direction in surface implantation technologies, according to [153], is the acceleration of laser plasma ions in a microwave cavity.

\section{From Microwave-Induced Charge Carrier Drift in Materials to Accelerator-Assisted Microwave Catalymetry and Accelerated Enthrakometric Catalysis}

It should be noted that microwave methods are widely used in the collective acceleration of elementary particles in the context of the acceleration of quasineutral plasma by microwaves, and relativistic magnetrons are used in many applications to accelerate ions and generate and amplify microwave radiation. Taking into account the long-term (more than 50 years) international experience of working with masers and accelerators (including ion accelerators) based on cyclotron autoresonance (for example, see [154]), one can come to the conclusion that most of these methods directly relate to the possibility of accelerating surface and near-surface processes.

Strictly speaking, microwave acceleration in this case does not differ significantly from laser acceleration-the mechanism, commonly known as acceleration by a near-surface layer of heated electrons, which is based on the ionization of the surface layer by laser (or microwave field) up to the formation of high-density plasma.

To obtain quasimonoenergetic spectra of accelerated ions, gold/platinum films with a deposited layer of hydrogen or carbon atoms are used in such methods. It is easy to see the similarity and compatibility of these approaches with enthrakometric methods in the microwave field, and, in addition, with beam-activated on-chip catalymetry. Much experience has been accumulated since the 1940s-1950s $[155,156]$ on the use of microwave radiation from different subbands in the acceleration of particles and the construction of microwave accelerators of particles of different types, beginning with klystron two-beam accelerators [157], microwave undulators [158] and conventional microwave linear accelerators [159], and ending with autoresonance (up to multimegawatt) aggregates [160-162], accelerators based on free-electron lasers, including inverse and narrow-band phase control ones [163,164], as well as inverse Cherenkov accelerators [165] (apart from microwave ion sources for accelerator mass spectrometry and Van de Graaff generators/accelerators as research tools [166-168]). These approaches and experimental data can, in the long term, be used to develop hybrid methods of "accelerating enthrakometric catalysis", and also (taking into account the works on accelerators using thermionic cathodes for microwave installations [169] and the possibility of using platinum in impregnational and dispenser sputtered cathodes [170-172]) provide the prospects of using eroded enthrakometers and enthrakometric electrode chips in an alternating mode as the detector and the source alternately, depending on the polarity and geometry/topology of the supply path. This gives a new source of feedback for monitoring and regulating the state of both the chip and the induced/activated/accelerated chemotronic phenomena on it. 


\section{Microwave Acceleration of Chemical Reactions and Microwave Catalysis}

Many chemical reactions are specifically (component- or product-selectively) accelerated by the microwave field [173]. Among the accelerated microwave chemical processes are many well-known reactions such as the Diels-Alder reaction [174], the Friedel-Crafts reaction [175], the reaction of $\mathrm{N}$-arylation, phosphorylation [176], methylation of starch [177], methylation of phenols, indoles and benzimidazoles [178], metathesis of olefins [179], addition reactions in the synthesis of allyl amines [180], modern processes of the so-called "Click chemistry" with modified nucleic acids [181], and the Suzuki or Suzuki-Miyaura reaction [182]. The latter reaction is equifinal with the Sonogashira reaction, and the basic reaction processes and stages of the catalytic cycles of Sonogashira and Suzuki reactions (i.e., oxidative addition, trans-metalation, reductive elimination) are similar, being the processes catalyzed by NHC-palladium complexes.

Nevertheless, it is known that Sonogashira has investigated remetalation of copper acetylides in reaction with platinum. This process proved to be no less effective than the alkyne remetallation in the presence of palladium, and the resulting acetylides of platinum effectively interacted with terminal alkynes. Therefore, it is possible to conduct the above equifinal processes on catalymetric chips with platinum enthrakometers under conditions of specific acceleration by the microwave field. Reactions of the latter type may, in part, be described as autocatalytic, as the agglomeration mechanisms of the metal-catalyst involved in the remetallation (e.g., Pd), are autocatalytic and indifferent to the introduction of the additional amounts of catalyst (therefore there is no need to replace the enthrakometer) [183-185].

The most recent studies have shown that acceleration of many chemical reactions by microwave irradiation cannot be achieved by conventional heating under otherwise identical temperature conditions. Hence, the interaction between the microwave radiation field and the catalyst itself is responsible for the catalytic effect [186]. Some authors suggest the decrease in the apparent activation energy is the main mechanism of the microwave-induced enhancement of the reaction rates [187], while others attribute the microwave-specific effects to selective heating [188] and emphasize the unique features of heat and mass transfer processes under microwave irradiation [189]. However, despite the controversial explanations of the nature of the above phenomenon, microwave acceleration of chemical reactions has recently found many scientific and industrial applications [190]. Microwave-assisted heterogeneous catalysis has also made a significant contribution to the area of green and sustainable chemistry, especially solid acid/base catalysis and transition metal-catalyzed reactions in organic synthesis [191]. All of these areas can benefit from application of the enthrakometer lab-on-a-chip systems operating both as power meters and catalymetric instruments.

Methods and technologies of microwave catalysis, in most cases, are liquid-phase processes and processes on interfaces with a solid phase. They should not be confused with the methods of radiofrequency catalysis in the gas phase, which are, rather, an exception to the rule rather than a separate direction of accelerating the chemical reactions [192-195]. Indeed, most relevant technologies for gas-phase radiofrequency stimulation of reactions, first, operate in the wavelength/frequency bands corresponding to energies not exceeding 1 millielectron-volts; secondly, they do not have a reasonable non-contradictory physical explanation of the effects observed and are not reproduced in a number of repetitions; and thirdly, are know-how or patent property of the companies that registered them, or the authors of the inventions, as a result of which they may contain a number of purposeful distortions (including misinformation against "technical espionage"). All this reduces the heuristic value of public descriptions of these methods to zero.

\section{Chemical Generation and Reception of Radio- and Microwaves and Microwave Spin Catalysis}

Buchachenko and Frankevich in 1994 explained the effects of the generation and action of radioand microwaves in physicochemical processes in the monograph "Chemical Generation and Reception of Radio- and Microwaves" [196]. In accordance with the ideas of chemical radiophysics [197], reactions 
can not only be accelerated by the radio-frequency field, but can also be a source of the radio-frequency field with the frequency predictable from the first principles. Academician A.L. Buchachenko from the Russian Academy of Sciences was the first to develop this concept as well as a chemical maser based on these principles [198,199]. Within the framework of microwave spin chemistry, the effects of "microwave catalysis" in a large number of cases are reduced to the phenomena of the so-called "spin catalysis": microwave pumping of radical pairs induces electron-spin transitions, and when the frequency coincides with the frequencies of magnetic resonance transitions (electron spin resonance) in radicals, spin conversion is accelerated and the yield of the products is increased. The nuclei orientation serves as a criterion of selective impact and specificity with respect to individual reactions (pumping at the frequencies of the components of the hyperfine EPR spectrum structure). In such "microwave-catalyzed" reactions, irradiation stimulates the formation of molecules with a definite spin orientation. It is also possible to catalyze the fractionation of isotopes in the microwave field-the so called microwave magnetic isotope effect [200].

Therefore, at present there is a prospect for creating a microwave-controlled chemical microfluidics in the format of spin catalysis microreactors, in which the functions of both detection and induction will be performed by the same chemical radiophysics principles, which ensure both reception of a microwave signal at the molecular level, and the generation of characteristic radio signals. In catalysis on metals and metal complexes when radical or ion-radical pairs are generated, metals or metal complexes are able to work as spin catalysts [201,202]. Therefore, one can assume that platinum of the enthrakometric chip can also participate in spin catalysis.

According to the literature sources, spin catalysis on platinum is observed in many classical methods associated with the use of platinum as a conventional catalyst: when methane and hydrogen are activated on platinum [203,204], in the oxidative decarboxylation of glycine in a magnetic field [205], etc. Given that one of the leading authors in this field is also the author of many works on platinum compounds [206-211], we may consider the source of ideas about the role of Pt in spin catalysis in these reactions as reliable and relevant.

\section{Towards Microwave-Controlled Magnetic and Isotope Ion Spintronics}

The microwave magnetic isotope effect, potentially implementable on a chip, intended for enthrakometric measurements (or, more precisely, in the material of the chip [212]) can be used to create fundamentally new types of devices for "microwave-controlled magnetic and isotope ion spintronics" or "microwave isotope spin ionics". It must be said that these trends, though seemingly exotic, are the logical continuation of the well-developed areas. For years, microwave spintronics (performed using magnetic resonance methods [213]) has been published in world-leading scientific journals [214].

The EU allocates sufficient funding on microwave spintronics projects not only for the fundamental, but also for the applied research. In 2013-2016, the European Commission financed in the framework of the CORDIS project "Microwave Spintronics as an Alternative Path to Components \& Systems for Telecommunications, Storage \& Security Applications" (program FP-7; FP-7-ICT-2011-85) under the ICT-2011.3.1 heading "Very advanced nanoelectronic components: design, engineering, technology and manufacturability") [215]. In the Russian Federation, applied microwave spintronics is promoted by the "Laboratory of Physics of Magnetic Heterostructures and Spintronics for Energy-Saving Information Technologies" of the Moscow Institute of Physics and Technology under the leadership of A.K. Zvezdin. In 2014, his laboratory proposed microwave spintronics for analyzing the spectral response of magnetic generators to the constant and high-frequency (up to $14 \mathrm{GHz}$ ) excitation signals [216].

On the other hand, "isotope spintronics" or "magneto-isotopic spintronics" have not yet been established as current trends, and therefore can be considered as future directions of development. For example, isotopically engineered spintronic materials for nuclear spin quantum computers are a field of intense interest within the NATO research programs [217]. Professor J.J. Morton from the London Center for Nanotechnology received a grant for the project "Quantum spintronics using donors in isotopically engineered silicon" (EP/H025952/2) [218], which was successfully completed in 2013. 
This project generated a number of works, which brought spintronics on a standard element base of microelectronics to an isotope-manipulatable format.

\section{From Magnetic Isotope On-Chip-Spintronics to MW-Nanospin-Ionics}

In contrast to spintronics, or spin electronics (a field of quantum electronics, based on spin-polarized transport or, as is often formulated, spin current transfer), the spin-based branch, which uses ions instead of electrons, belongs, by definition, to spin ionics, but not electronics. This fact significantly increases the novelty of our concept proposed, as the microwave or spin ionics on an active chip are a new trend, and the isotope aspect of the problem until recently has never been studied. The recent works on spin ionics were performed on the same carriers that were used by the authors of this paper [212] in the microwave field. However, the standard spin ionics does not imply the use of the microwave field.

The mechanism of cohesion between ionic conductivity and magnetic ordering proposed in [219] is related, in particular, with a phase transition with a charge transfer, ferroelectric dynamics, and reversible photomagnetism accompanied by high ionic conductivity. These emerging properties satisfy the requirements for the conceptual complexity of models that describe self-organizing systems in high-energy physical chemistry. Therefore, this approach can be implemented on a chip with a bolometric cell, and the enthrakometer, by definition, is a bolometric sensor in the microwave range. It follows that it is possible to implement specialized spin-ion bolometers on an enthrakometric chip in order to analyze magnetic isotopy and control it in real time as an alternative to spin current transfer/spin-polarized transport "controllability" in electronic systems. Currently, there is a transition from spin-ionics per se $[219,220]$ to nano-spin ionics (2016 project "Development of nano spin-ionics" by Yu Masaki Mizuguchi, FY 2014-2016 (Grant-in-Aid for Challenging Exploratory Research), Japan [221]), which fits the concept of microminiaturization of measuring and analytical devices well and the formation of a new culture of measurements-on-chip metrology, "labs-on-a-chip" (LoC).

\section{Enthrakometric Chips and LoCs as 3D Hybrid Integrated Circuits}

Enthrakometric chips, as well as film bolometers, operate on the same principle based on the change in resistance of the metal film under heating by microwave power. Therefore, enthrakometric chips can be interpreted as films, or, more precisely, as hybrid film integrated circuits. The surface relief ("Collard's meander" in radio engineering terminology) is formed in a similar way to the film integrated circuits, by repeated deposition of the metal films (gold, platinum-when the classical design of the gold leaf enthrakometer-electroscope and the Collard enthrakometer, respectively, is reproduced above) on a substrate. In standard enthrakometric measurements, any properties of the deposited layer apart from those participating in detection (of both absorbed power, measured in the same way as in the case of conventional-bolometric-power measurements and of the ratio between the absorbed and the passing power because a classical enthrakometer measures the passing microwave power) can be neglected, because the enthrakometer does not perform any other operations on the incoming microwave signal and, according to an equivalent circuit, does not interact with other devices that change the nature of the response.

In our case, when the enthrakometer is introduced as an element of a microfluidic catalymetric system with its own electrochemical characteristics that change the character of the bolometer or enthrakometer with which the substance interacts as with a microelectrode, the properties of the deposited layer cannot be disregarded because each electrochemical configuration with known frequency and impedance characteristics corresponds to a certain equivalent scheme. For sputtered film enthrakometers, this has been demonstrated on a frequency response analyzer (FRA) and an equivalent circuit analyzer with differential coulometry spectroscopy (DCS) options and structural electrochemical circuit modeling software, although not at microwave frequencies, as the latter requires costly and, unfortunately, inaccessible composite analyzers (for example, E5061B-3L5 type, option 005) that measure impedance in up to a $3-\mathrm{GHz}$ range and analyze equivalent circuits. Therefore, unlike the 
enthrakometer as a sensor in conventional bridge circuits, the enthrakometer as an active element in contact with systems with a double electrical layer (considered as a capacitor) and an "electrochemical load" in the form of systems exhibiting various electrochemical impedance spectroscopy (EIS) results must take into account the equivalent circuits of these structures, as if they were included in the hybrid microcircuit at the stage of its operation.

For example, theoretical analysis and design of microwave microassemblies, including non-standard microassemblies, in the former USSR since 1976, have been regulated by the Industry Standard OST 4G0.010.201 (version 1-75, OST 4G0.010.018) “Design of the Microwave Microassemblies". There are many accessible works on the topic of developing analog integrated microwave devices and feedline couplers/match boxes for hybrid microwave circuits [222,223]. However, it should be noted that the enthrakometer with electrochemically deposited layers is not considered as a planar film structure with a simple equivalent circuit, but only as a three-dimensional microwave integrated circuit with inhomogeneities and "sandwich-type" elements [224]. The enthrakometer as a power attenuator cannot be a source of accurate data on the measurement of the absorbed power. However, it is necessary to take into account the power absorbed by the layers on the enthrakometer surface or in the circuits. If the circuits are present, they should be accounted for in any measurements related to the attenuation data. The "self-consistency" of errors, or the fact that attenuation measurement error during instrument calibration (by methods associated with the attenuation measurements) turns into its systematic error, should be treated as a compensating factor.

When a microfluidic chip is positioned on a plane, normal to the waveguide axis, it shunts the waveguide with active resistance close to the wave resistance, which ensures good chip matching. However, the analysis of the observed phenomena must consider the medium deposited on a chip. This, in particular, requires taking into account the temperature gradient related to the redistribution of the absorbed power density in accordance with the chemical composition or the structure of the test substance, as well as the difference in the amplitude of the electromagnetic wave in the enthrakometer heating zones and in substances located on it. This can be partly calculated using different software: for the "initial" enthrakometer, high frequency structural simulator (HFSS) software or its analogs are used.

\section{Separation of Thermal and Non-Thermal Effects of the Microwave Field in MW-Induced Self-Organization Processes on the Surface of Enthrakometric Chips}

Among factors that affect the distribution of amplitudes and radiation patterns at the enthrakometer on a chip and the chemical system on it are: different (but correlated with the wave direction) nature of the structures in the microwave-induced self-organization processes (first observed by Gradov's group in 2009-2012, but interpreted too broadly, with no correlation with the angular characteristics and some errors in data interpretation [225]); and the effect of radiation patterns on the efficiency of microwave thermal analysis of some anisotropic-heterogeneous structures on a chip [226]. Other criteria for the microwave-induced self-organization on a chip include the standing and traveling wave coefficients, as well as the attenuation coefficient [227], which also affect the medium temperature, spatially modulate the amplitude of the wave, and determine the heat transferred to the system.

A specific device for simultaneous monitoring of different parameters during microwave-induced self-organization in the active colloidal media has been recently developed by Gradov's group. To establish correlation between the thermophysical efficiency of the medium heating (due to the absorbed power) and the physical parameters of the magnetron used in the initial experiments to produce effects of the microwave-induced self-organization, a monitor panel for the above parameters was developed and connected to a multichannel analog-to-digital converter (ADC). The monitor panel included: a kilovoltmeter (as the secondary winding of the high-voltage transformer as well as the voltage doubling circuit on a high-voltage capacitor generate voltage up to $\approx 4 \mathrm{kV}$ to power the magnetron anode), a thermometer $\left(300{ }^{\circ} \mathrm{C}\right.$ to $900{ }^{\circ} \mathrm{C}$ range for the cases of microwave melting and BSD-like technologies \{Black Solar Dom, LG\} for processing soft matter), a milliammeter (as the anode current 
reaches $\approx 300 \mathrm{~mA}$ ), and a decibelmeter (to analyze attenuation in special cases [227]). In addition to the dial gauges with the characteristic inertia, the panel includes buttons (switches, in the earlier version) to transfer the signal to the ADC.

Besides impedance spectroscopic analysis and microwave measurements, the above electrochemical/ microwave photochemical [228] analyzer (based on the analogy between microwave photochemistry/microwave optoelectronics with microwave electrochemical induction in self-organization processes on a chip, and photochemistry/optoelectronics in UV-NIR regions in reaction-diffusion processes on chips with the excitation sources in the above bands [229]) allows one to quantitatively characterize self-organization processes in the microwave field by a number of complementary descriptors, providing one-to-one correspondence of their pools with the results of the self-organization processes on a chip (in the ideal case, with the positional sensitivity, given the reaction-diffusion nature of self-organization.

\section{Towards Multiparametric Chemosensing and Physico-Chemical Sensing on the Collard Enthrakometer Surface}

The possibility of using recording elements with an active surface, such as platinum enthrakometers, as catalymetric electrodes or solid-state chemotronic elements for measurements in a microwave field were considered above. However, the range of enthrakometric measurements and the nomenclature of the corresponding variables are limited. As a result, the users of systems designed to measure processes on the active surface of enthrakometers generally do not receive comprehensive information about the mechanism of microwave-induced or microwave-activated processes in the medium under investigation. Particularly important is the lack of knowledge on complementary descriptors in biophysical studies and in studies on microwave-induced self-organization in heterogeneous media or composite structures, known to have a multifactor response and a certain structural and chemical selectivity for microwave pumping [225].

It is obvious that self-organization of structures is characterized not only by the power of the microwave effect inducing or activating the structure formation, but also by the mechanical and microhydrodynamic displacements in the medium, by stretching and compression in zones of differing composition and structure, by isotropy distortions (anisotropy) and the appearance of oriented or asymmetric nonequilibrium structures under the external fields (in particular, in the magnetic field under magnetron treatment on iron-containing particles [230], including microwave-generated structures, which are initially absent in the precursor). In such cases, the configuration of the microwave field determines the shape of the gradient fields of the newly-forming particles, or of both particles and aggregated structures on their basis [231].

A complex study of the processes on enthrakometric chips should imply not only the power measurement (equivalent to the measurements on a bolometer, which, like the enthrakometer, is included in the bridge circuit to indicate the absorbed power) and, in rare exotic cases, catalymetry, but also tensometry of the medium (when the tensor-resistive method requires the use of the Wheatstone bridge) and magnetometry (for the processes in which a magnetron or analogous magnetron-type devices are a microwave source: the platinotron that differs from the magnetron in the topology of the open-loop resonator system; the amplitron equivalent to the platinotron in a microwave amplification mode; and the stabilotron, different from the above by the presence of additional devices in the generator circuit, which provides positive feedback). Obviously, in order to establish accurate correlations between the effecting factors, intermediate factors that appear in the medium under microwave treatment, and the resulting factors, which are the consequence of the first two, but which, being a response, differ from them both qualitatively and energetically, one should conduct measurements on a single instrument-without changing the sensor (which, in case of using the active surface is impossible and affects the process) and the relative shift of the sensor and the measured object. This requirement for the analysis of heterogeneous self-organizing systems is related in particular to the need for a position-sensitive measurement and establishment of localization and mutual colocalization 
(spatial correlation) of the microwave power and temperature, on the one hand, and the resultant properties (magnetic, tensometric, etc.), on the other hand.

To analyze the possibility of combining such measurements on a surface of a single chemosensor, an enthrakometer, one should turn to the topology of the simple platinum and gold Collard enthrakometers [1-3]. The Collard lattice (Figure 1a), enclosed in a reconfigurable cell (Figure 1b), is not geometrically unique. A similar geometry is typical of many tensoresistors, multilayer magnetoresistors with magnetically different layers in the shape of a meander, and sensors based on surface acoustic waves (SAW) with counter-pin or counter-comb converters.

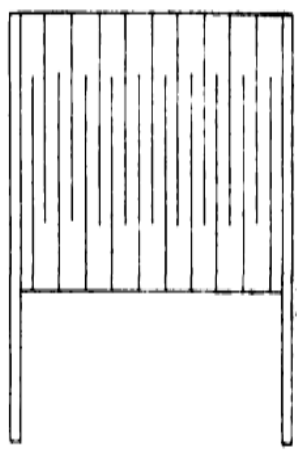

(a)

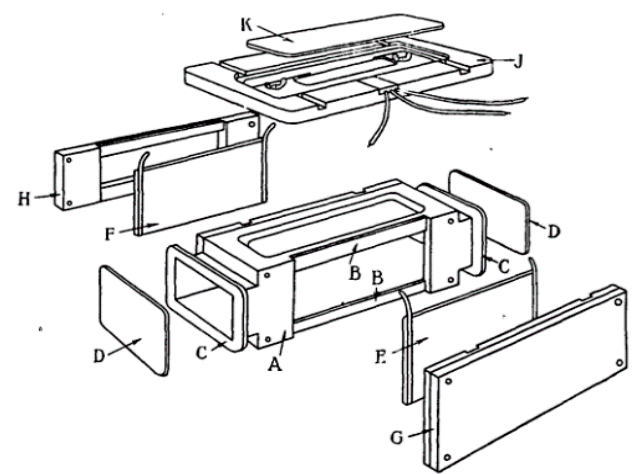

(b)

Figure 1. (a) The enthrakometer grid, (b) The grid assembly (by Collard) [2]. Reproduced with permission of the Institution of Engineering and Technology.

The number of meanders is not important. In a certain range of parameters, it is possible to assemble on a single layer an enthrakometer, a SAW sensor with counter-pin geometry, a magnetoresistor or a magnetostrictive sensor (that in recent years was repeatedly hybridized with a SAW sensor with the same geometry [232]), and a microfluidic set of channels located between meanders of the sensor layers, or within them, or above them. Compatibility of magnetic sensors of such geometry with liquid media was recently demonstrated in NASA [233], indicating a trend of introducing them into microfluidics and ferrohydrodynamics [234]).

It should be noted that the measurement and indication of the magnetic field effects of magnetron devices in microwave-induced processes of anisotropic self-organization on a chip with a magnetoresistive enthrakometer hybridized with a SAW sensor creates qualitatively new branches of acoustofluidics or microfluidics on surface acoustic waves $[235,236]$ : "microwave chemo-acoustofluidics" and "magnetic chemo-acoustofluidics". For example, surface acoustic waves can be generated by ferroelectric polymers such as PVDF, providing a reversible conversion of the acoustic field into the electric one (and vice versa), in particular, taking into account the features of cooperative mobility in the amorphous phase of ferroelectric polymers [237]. Considering the spectral response of the dyes introduced into the ferroelectric polymer matrix, registration of the physical and chemical processes occurring in such devices becomes possible due to the spectral shifts observed [238,239].

This ensures the qualitative novelty of descriptors analyzed by this type of device. The authors succeeded in creating a control system for magnetofluid flows (due to instabilities, based simultaneously on magnetic and ultrahigh-frequency effects synchronized by using the same magnetron device as a source of magnetic field and microwave excitation of a chip) on such a flexibly configurable architecture with non-solid channels controlled by an external field [240,241] and localized outside the channels of the microwave enthrakometer. It is possible to eliminate the overlap of descriptor signals on the chip because the layers of the meander that perform certain functions will not perform other functions (spatial separation), or with the relative pulse duration of each measuring process, the relaxation time of the parameters during each measurement cycle will be shorter than the time until the data collecting 
mode stops and the new measurement cycle with another parameter begins (for which the first unfixed parameter is a passive interval) - temporal separation.

From our perspective, it is possible to integrate the new features of laser spectroscopy into the above system (TDLS, particularly, TDLAS based on vertically emitting lasers, VSCEL, or DFB-lasers with distributed feedback) [227]. However, their application is limited to the catalymetric processes in which one of the products or reagents is present in the gas phase (similar to most methods of intracavity absorption spectroscopy, such as CRDS / CRLAS, NICE-OHMS, etc.). From the kinetic point of view, the concepts and technologies of control of the microwave-induced self-organization on chips using gas laser spectroscopy as a complementary method give a new analytical tool in microwave photochemistry [227], suggested by Církva et al. [228].

In summary, the following potential application areas in fundamental studies, particularly in physical and analytical chemistry and electrochemistry, can be suggested for the devices proposed:

- Electrochemical sensing and microwave-enhanced electroanalysis

- Studies of the adsorption phenomena at the microwave range

- Microwave catalymetry and analysis of the mechanisms of microwave catalysis

- Study of the intermetallic compound formation, electrosynthesis of organometalic compounds and intermediates

- Combination of the microwave sample preparation with microwave operando spectroscopy on the enthrakometric surface

- High-frequency thermal analysis on the enthrakometric chip

- Kinetic analysis of the microwave-induced processes on the surface of platinum enthrakometers

- Combination of electrochemical measurements on the polarographic enthrakometric electrodes with EPR methods in a microwave range

- Monitoring of generation of the reactive radical species in aqueous systems during electrochemical measurements

- Capillary electrophoresis, including electrophoresis in radio frequency fields.

Beyond the above mentioned fundamental application areas, there are also a number of industrial applications where enthrakometric labs-on-a-chip can also be rather useful, such as:

- Operando spectroscopy in catalytic microreactors for the fine chemical synthesis

- Design of novel hybrid sensors combining bolometers and chemosensors

- Design of chemotrons and chemotronic devices for electrochemical engineering

- Local microwave regulation of the synthesis processes on the surface of a platinum chip-enthrakometer as an absorber of microwave power

- Thermal diffusion Pt-doping of superionic materials during their microwave-induced formation on a platinum surface of the enthrakometer

- Design of the devices providing the microwave field-assisted ion transport and ion exchange (e.g., during the glass hardening process)

- Application of enthrakometers for technological control in microwave accelerators, from klystron two-beam accelerators, microwave undulators and conventional microwave linear accelerators to auto-resonant aggregates and inverse Cherenkov accelerators

- Integration of several types of physical sensors for industrial processes on a single platform (multilayer and multi-meander sensors on the enthrakometer platform).

Acknowledgments: This work was carried out in the framework of the State Assignment of Ministry of Science and Higher Education of the Russian Federation (project 0082-2018-0006, registration code AAAA-A18-118020890097-1).

Conflicts of Interest: The authors declare no conflict of interest. 


\section{References}

1. Collard, J. The gold-leaf electroscope and the Enthrakometer. J. Inst. Electr. Eng. Part 3A 1946, 93, $209-211$. [CrossRef]

2. Collard, J. The Enthrakometer, an instrument for the measurement of power in rectangular wave guides. J. Inst. Electr. Eng. Part 3A 1946, 93, 1399-1402. [CrossRef]

3. Collard, J. The measurement of voltage at centimetre wavelengths. J. Inst. Electr. Eng. Part 3A 1946, 93, 1393-1398. [CrossRef]

4. Hinton, L.J.T.; Burry, L.F. An Enthrakometer for the Band 26.0-40 Gc/s'; Document CP 198; EMI Electronics Ltd.: London, UK, 1959.

5. Fantom, A. Radio Frequency and Microwave Power Measurement. In IEE Electrical Measurement Series; IET-Peter Peregrinus Ltd.: London, UK, 1990; Volume 7, p. 278.

6. Adamovich, E.D.; Gradov, O.V.; Nasirov, P.A. Liquid metal microfluidics with morphometric monitoring: From liquid metal antenna towards the radiofrequency polarography. Fundam. Prob. Radioengineering Device Constr. 2018, 18, 650-653. (In Russian)

7. Lan, W.G.; Wong, M.K.; Sin, Y.M. Microwave digestion of fish tissue for selenium determination by differential pulse polarography. Talanta 1994, 41, 53-58. [CrossRef]

8. Yi, H.; Zhang, T.M.; Cao, J.; Liang, Y.-Z. Microwave digestion polarography for determining seven trace elements in Salvia Miltiorrhiza root and compound Salvia Militiorrhiza root injection simultaneously. J. Cent. South Univ. Technol. 2007, 14, 514-519.

9. Romero, R.A.; Tahán, J.E.; Moronta, A.J. Two alternative sample mineralization procedures to permit subsequent polarographic determination of total soluble aluminium in haemodialysis water. Anal. Chim. Acta 1992, 257, 147-154. [CrossRef]

10. Jee, R.D. Fast sweep a.c. polarography. Fresenius' Zeitschrift für Analytische Chemie 1973, 264, $143-146$. [CrossRef]

11. Barker, G.C.; McKeown, D. Modulation Polarography of DNA and Some Types of RNA. Bioelectrochem. Bioenerg. 1976, 3, 373-392. [CrossRef]

12. Stas', I.E.; Nedyakina, I.A.; Shipunov, B.P. Determination of potassium and sodium in non-aqueous solvents by stripping voltammetry in a radio-frequency electromagnetic field. J. Anal. Chem. 2003, 58, 959-964. [CrossRef]

13. Devanathan, M.A.V.; Abeyagunawardene, S. Faradaic rectification studies of redox systems at radiofrequencies. J. Electroanal. Chem. Interfacial Electrochem. 1975, 62, 195-208. [CrossRef]

14. McCord, T.G.; Smith, D.E. Second harmonic alternating current polarography. Considerations of the theory of quasi-reversible processes. Anal. Chem. 1968, 40, 289-304. [CrossRef]

15. McCord, T.G.; Smith, D.E. Second harmonic a.c. polarography. Theoretical predictions for systems with first-order chemical reactions following the charge transfer step. Anal. Chem. 1969, 41, 1423-1441. [CrossRef]

16. Hayes, J.W.; Ruić, I.; Smith, D.E.; Booman, G.L.; Delmastro, J.R. Fundamental harmonic a.c. polarography with irreversible dimerization following the charge transfer step: Theory and experimental results with the benzaldehyd system. J. Electroanal. Chem. 1974, 51, 269-285. [CrossRef]

17. Ruzic, I.; Sobel, H.R.; Smith, D.E. On the theory for D.C. and fundamental harmonic a.c. polarography with the first-order consecutive ECE mechanism. J. Electroanal. Chem. Interfacial Electrochem. 1975, 65, 21-56. [CrossRef]

18. Ogawa, N.; Watanabe, I.; Ikeda, S. Analytical application of second-harmonic a.c. polarography. Anal. Chim. Acta 1982, 141, 123-129. [CrossRef]

19. Fleet, B.; Jee, R.D. An evaluation of integration procedures for improving the precision of a.c. polarography. J. Appl. Electrochem. 1971, 1, 269-274. [CrossRef]

20. Zheleztsov, A.V. Resolving power in voltametry and polarography. Meas. Tech. 1989, 32, 1211-1214. [CrossRef]

21. Bauer, K.-H. Calculation of voltammetric peaks by the transformed Heyrovsky-Ilkovič equation. Simulation of polarograms, smoothing of voltammetric peaks, separation of overlapping peaks. Fresenius' J. Anal. Chem. 1990, 336, 665-671. [CrossRef]

22. Zheleztsov, A.V. A Solution voltammetry method. Meas. Tech. 2002, 45, 445-451. [CrossRef] 
23. Kambara, T.; Watarai, S. The temperature dependence of the radio-frequency polarographic wave height. Bull. Chem. Soc. Jpn. 1966, 39, 521-524. [CrossRef]

24. Tsuji, K. Studies on the suspended particles in air. I. Determination of copper, lead, cadmium and zinc in air by low temperature radio frequency oxidation apparatus and polarography. Eisei Shikenjo Hokoku 1971, 89, 21-24. (In Japanese) [PubMed]

25. Šesták, J.; Mareš, J.J. From caloric to stathmograph and polarography. J. Therm. Anal. Calorim. 2007, 88, 763-768. [CrossRef]

26. Tsai, Y.C.; Coles, B.A.; Compton, R.G.; Marken, F. Microwave activation of electrochemical processes: Enhanced electrode halogenation in organic solvent media. J. Amer. Chem. Soc. 2002, 124, 9784-9788. [CrossRef] [PubMed]

27. Sur, U.K.; Marken, F.; Coles, B.A.; Compton, R.G.; Dupont, J. Microwave activation in ionic liquids induces high temperature-high speed electrochemical processes. Chem. Commun. 2004, 24, 2816-2817.

28. Ghanem, M.A.; Compton, R.G.; Coles, B.A.; Canals, A.; Vuorema, A.; John, P.; Marken, F. Microwave activation of the electro-oxidation of glucose in alkaline media. Phys. Chem. Chem. Phys. 2005, 7, 3552-3559. [CrossRef]

29. Bae, S.-E.; Gokcen, D.; Liu, P.; Mohammadi, P.; Brankovic, S.R. Size effects in monolayer catalysis-model study: Pt submonolayers on Au (111). Electrocatalysis 2012, 3, 203-210. [CrossRef]

30. Lee, K.; Zhang, J.; Wang, H.; Wilkinson, D.P. Progress in the synthesis of carbon nanotube- and nanofiber-supported Pt electrocatalysts for PEM fuel cell catalysis. J. Appl. Electrochem. 2006, 36, 507-522. [CrossRef]

31. Konsolakis, M.; Yentekakis, I.V. Insight into the role of electropositive promoters in emission control catalysis: An in situ drifts study of no reduction by $\mathrm{C}_{3} \mathrm{H}_{6}$ over Na-promoted $\mathrm{Pt}_{2} \mathrm{Al}_{2} \mathrm{O}_{3}$ catalysts. Top. Catal. 2013, 56, 165-171. [CrossRef]

32. Mirdamadi-Esfahani, M.; Mostafavi, M.; Keita, B.; Nadjo, L.; Kooyman, P.; Remita, H. Bimetallic Au-Pt nanoparticles synthesized by radiolysis: Application in electro-catalysis. Gold Bull. 2010, 43, 49-56. [CrossRef]

33. Sharma, S.; Singh, P.; Hegde, M.S. Electrocatalysis and redox behavior of $\mathrm{Pt}^{2+}$ ion in $\mathrm{CeO}_{2}$ and $\mathrm{Ce}_{0.85} \mathrm{Ti}_{0.15} \mathrm{O}_{2}$ : XPS evidence of participation of lattice oxygen for high activity. J. Solid State Electrochem. 2011, 15, 2185-2197. [CrossRef]

34. Gasteiger, H.A.; Marković, N.M.; Ross, P.N. Structural effects in electrocatalysis: Electrooxidation of carbon monoxide on $\mathrm{Pt}_{3} \mathrm{Sn}$ single-crystal alloy surfaces. Catal. Lett. 1996, 36, 1-8. [CrossRef]

35. Yang, Z.; Miao, Y.; Xu, L.; Song, G.; Zhou, S. Adsorption of Bi(III) on Pt nanoparticles leading to the enhanced electrocatalysis of glucose oxidation. Colloid J. 2015, 77, 382-389. [CrossRef]

36. Verheij, L.K.; Hugenschmidt, M.B.; Freitag, M.; Poelsema, B.; Comsa, G. Deuterium-Oxygen Reaction on Pt (111) Catalysis by Defects. In Fundamental Aspects of Heterogeneous Catalysis Studied by Particle Beams; Springer: Boston, MA, USA, 1991; pp. 445-450.

37. Bernfeld, G.J.; Bird, A.J.; Edwards, R.I.; Köpf, H.; Köpf-Maier, P.; Raub, C.J.; te Riele, W.A.M.; Simon, F.; Westwood, W. Platinum-group metals, alloys and compounds in catalysis. In Gmelin Handbook of Inorganic Chemistry, 8th ed.; Part Pt. (System No. 68), Suppl. Vol. A 1; Springer: Berlin/Heidelberg, Germany, 1985; pp. 92-317.

38. Kurkina, E.S.; Makeev, A.G. Bifurcation analysis of the mathematical model of the $\mathrm{NO}+\mathrm{CO} / \mathrm{Pt}(100)$ reaction. Comput. Math. Model. 1997, 8, 326-347. [CrossRef]

39. Hartmann, N.; Imbihl, R.; Vogel, W. Experimental evidence for an oxidation/reduction mechanism in rate oscillations of catalytic $\mathrm{CO}$ oxidation on $\mathrm{Pt} / \mathrm{SiO}_{2}$. Catal. Lett. 1994, 28, 373-381. [CrossRef]

40. Eiswirth, R.M.; Krischer, K.; Ertl, G. Nonlinear dynamics in the CO-oxidation on Pt single crystal surfaces. Appl. Phys. A 1990, 51, 79-90. [CrossRef]

41. Chabal, Y.J.; Christman, S.B.; Burrows, V.A.; Collins, N.A.; Sundaresan, S. Self-sustained kinetic oscillations in the catalytic co oxidation on platinum. In Kinetics of Interface Reactions. Springer Series in Surface Sciences; Springer: Berlin/Heidelberg, Germany, 1987; Volume 8, pp. 285-295.

42. Kurkina, E.S.; Malykh, A.V.; Makeev, A.G. Natural waves and chaotic structures in a distributed fourcomponent model of the $\mathrm{NO}+\mathrm{CO} / \mathrm{Pt}(100)$ reaction. Comput. Math. Model. 1999, 10, 363-378. [CrossRef]

43. Kurkina, E.S.; Semendyaeva, N.L. Oscillatory dynamics of CO oxidation on platinum-group metal catalysts. Kinet. Catal. 2005, 46, 453-463. [CrossRef] 
44. Krylov, O.V.; Shub, B.R. Nonequilibrium Processes in Catalysis; CRC Press: Boca Raton, FL, USA; Ann Arbor, MI, USA; London, UK; Tokyo, Japan, 1993; p. 320.

45. Privman, V.; Gorshkov, V.; Zavalov, O. Formation of nanoclusters and nanopillars in nonequilibrium surface growth for catalysis applications: Growth by diffusional transport of matter in solution synthesis. Heat Mass Transfer 2014, 50, 383-392. [CrossRef]

46. Solovyev, A.L.; Dmitriev, V.M.; Agafonov, A.B. Nonequilibrium properties of HTSC under microwave irradiation. In Electronic Properties of High-Tc Superconductors. Springer Series in Solid-State Sciences; Springer: Berlin/Heidelberg, Germany, 1993; Volume 113, pp. 99-103.

47. Dorozhkin, S.I. Self-Oscillations of a spontaneous electric field in a nonequilibrium two-dimensional electron system under microwave irradiation. JETP Lett. 2015, 102, 91-95. [CrossRef]

48. Devyatov, I.A.; Krutitskii, P.A.; Semenov, A.V.; Goncharov, D.V. Nonequilibrium fluctuations of a thin metal diffuse film exposed to microwave radiation. JETP Lett. 2008, 88, 254-258. [CrossRef]

49. Burla, M.; Cortés, L.R.; Li, M.; Wang, X.; Chrostowski, L.; Azaña, J. On-chip programmable ultra-wideband microwave photonic phase shifter and true time delay unit. Opt. Lett. 2014, 39, 6181-6184. [CrossRef] [PubMed]

50. Zhuang, L.; Hoekman, M.; Taddei, C.; Leinse, A.; Heideman, R.G.; Hulzinga, A.; Verpoorte, J.; Oldenbeuving, R.M.; van Dijk, P.W.; Boller, K.J.; et al. On-chip microwave photonic beamformer circuits operating with phase modulation and direct detection. Opt. Express 2014, 22, 17079-17091. [CrossRef] [PubMed]

51. Zhuang, L.; Taddei, C.; Hoekman, M.; Leinse, A.; Heideman, R.; van Dijk, P.; Roeloffzen, C. Ring resonator-based on-chip modulation transformer for high-performance phase-modulated microwave photonic links. Opt. Express 2013, 21, 25999-26013. [CrossRef]

52. Marpaung, D.; Roeloffzen, C.; Leinse, A.; Hoekman, M. A photonic chip based frequency discriminator for a high performance microwave photonic link. Opt. Express 2010, 18, 27359-27370. [CrossRef]

53. Pagani, M.; Marpaung, D.; Choi, D.Y.; Madden, S.J.; Luther-Davies, B.; Eggleton, B.J. Tunable wideband microwave photonic phase shifter using on-chip stimulated Brillouin scattering. Opt. Express 2014, 22, 28810-28818. [CrossRef]

54. Choudhary, A.; Aryanfar, I.; Shahnia, S.; Morrison, B.; Vu, K.; Madden, S.; Luther-Davies, B.; Marpaung, D.; Eggleton, B.J. Tailoring of the Brillouin gain for on-chip widely tunable and reconfigurable broadband microwave photonic filters. Opt. Lett. 2016, 41, 436-439. [CrossRef]

55. Byrnes, A.; Pant, R.; Li, E.; Choi, D.Y.; Poulton, C.G.; Fan, S.; Madden, S.; Luther-Davies, B.; Eggleton, B.J. Photonic chip based tunable and reconfigurable narrowband microwave photonic filter using stimulated Brillouin scattering. Opt. Express 2012, 20, 18836-18845. [CrossRef]

56. Li, J.; Lee, H.; Vahala, K.J. Microwave synthesizer using an on-chip Brillouin oscillator. Nat. Commun. 2013, 4, 2097. [CrossRef]

57. Hammer, J.; Thomas, S.; Weber, P.; Hommelhoff, P. Microwave chip-based beam splitter for low-energy guided electrons. Phys. Rev. Lett. 2015, 114, 254801. [CrossRef]

58. Hoffrogge, J.; Fröhlich, R.; Kasevich, M.A.; Hommelhoff, P. Microwave guiding of electrons on a chip. Phys. Rev. Lett. 2011, 106, 193001. [CrossRef] [PubMed]

59. Obata, T.; Pioro-Ladrière, M.; Kubo, T.; Yoshida, K.; Tokura, Y.; Tarucha, S. Microwave band on-chip coil technique for single electron spin resonance in a quantum dot. Rev. Sci. Instrum. 2007, 78, 104704. [CrossRef] [PubMed]

60. Buchachenko, A.L.; Kozhushner, M.A.; Shub, B.R. Tunneling spectroscopy of single electron spin. Russ. Chem. Bull. 1998, 47, 1683-1685. [CrossRef]

61. Kozhushner, M.A.; Shub, B.R.; Muryasov, R.R. On the experimental possibilities of observing single spins in STM. JETP Lett. 1998, 67, 508-512. [CrossRef]

62. Grishin, M.V.; Gatin, A.K.; Dokhlikova, N.V.; Kirsankin, A.A.; Kharitonov, V.A.; Belysheva, T.V.; Trakhtenberg, L.I.; Shub, B.R. Single electronic traps in tin and zinc oxides. Nanotechnol. Russ. 2014, 9, 151-156. [CrossRef]

63. Lacroute, C.; Reinhard, F.; Ramirez-Martinez, F.; Deutsch, C.; Schneider, T.; Reichel, J.; Rosenbusch, P. Preliminary results of the trapped atom clock on a chip. IEEE Trans. Ultrason. Ferroelectr. Freq. Contr. 2010, 57, 106-110. [CrossRef] 
64. Winger, M.; Blasius, T.D.; Mayer, A.T.P.; Safavi-Naeini, A.H.; Meenehan, S.; Cohen, J.; Stobbe, S.; Painter, O. A chip-scale integrated cavity-electro-optomechanics platform. Opt. Express 2011, 19, 24905-24921. [CrossRef]

65. Delbecq, M.R.; Schmitt, V.; Parmentier, F.D.; Roch, N.; Viennot, J.J.; Fève, G.; Huard, B.; Mora, C.; Cottet, A.; Kontos, T. Coupling a quantum dot, fermionic leads, and a microwave cavity on a chip. Phys. Rev. Lett. 2011, 107, 256804. [CrossRef]

66. Vo, T.D.; Pelusi, M.D.; Schröder, J.; Luan, F.; Madden, S.J.; Choi, D.Y.; Bulla, D.A.; Luther-Davies, B.; Eggleton, B.J. Simultaneous multi-impairment monitoring of $640 \mathrm{~Gb} / \mathrm{s}$ signals using photonic chip based RF spectrum analyzer. Opt. Express 2010, 18, 3938-3945. [CrossRef]

67. Tasselli, G.; Alimenti, F.; Fonte, A.; Zito, D.; Roselli, L.; De Rossi, D.; Lanatà, A.; Neri, B.; Tognetti, A. Wearable microwave radiometers for remote fire detection: System-on-Chip (SoC) design and proof of the concept. Conf. Proc. IEEE Eng. Med. Biol. Soc. 2008, 981-984. [CrossRef]

68. Burla, M.; Marpaung, D.; Zhuang, L.; Roeloffzen, C.; Khan, M.R.; Leinse, A.; Hoekman, M.; Heideman, R. On-chip CMOS compatible reconfigurable optical delay line with separate carrier tuning for microwave photonic signal processing. Opt. Express 2011, 19, 21475-21484. [CrossRef] [PubMed]

69. Linder, V.; Koster, S.; Franks, W.; Kraus, T.; Verpoorte, E.; Heer, F.; Hierlemann, A.; de Rooij, N.F. Microfluidics/CMOS orthogonal capabilities for cell biology. Biomed. Microdevices 2006, 8, 159-166. [CrossRef] [PubMed]

70. Liu, Y.; Smela, E.; Nelson, N.M.; Abshire, P. Cell-lab on a chip: A CMOS-based microsystem for culturing and monitoring cells. Conf. Proc. IEEE Eng. Med. Biol. Soc. 2004, 4, 2534-2537. [PubMed]

71. Ciftlik, A.T.; Gijs, M.A. Parylene to silicon nitride bonding for post-integration of high pressure microfluidics to CMOS devices. Lab Chip 2012, 12, 396-400. [CrossRef]

72. Huang, Y.; Mason, A.J. Lab-on-CMOS integration of microfluidics and electrochemical sensors. Lab Chip 2013, 13, 3929-3934. [CrossRef]

73. Khorasani, M.; Behnam, M.; van den Berg, L.; Backhouse, C.J.; Elliott, D.G. High-voltage CMOS controller for microfluidics. IEEE Trans. Biomed. Circuits Syst. 2009, 3, 89-96. [CrossRef]

74. Behnam, M.; Kaigala, G.V.; Khorasani, M.; Marshall, P.; Backhouse, C.J.; Elliott, D.G. An integrated CMOS high voltage supply for lab-on-a-chip systems. Lab Chip 2008, 8, 1524-1529. [CrossRef]

75. Ensslin, K.; Gustavsson, S.; Gasser, U.; Küng, B.; Ihn, T. A quantum mechanics lab on a chip. Lab Chip 2010, 10, 2199-2202. [CrossRef]

76. Chen, X.; Song, L.; Assadsangabi, B.; Fang, J.; Mohamed Ali, M.S.; Takahata, K. Wirelessly addressable heater array for centrifugal microfluidics and Escherichia coli sterilization. Conf. Proc. IEEE Eng. Med. Biol. Soc. 2013, 5505-5508. [CrossRef]

77. Zhang, W.; Zhang, H.; Williams, S.E.; Zhou, A. Microfabricated three-electrode on-chip PDMS device with a vibration motor for stripping voltammetric detection of heavy metal ions. Talanta 2015, 132, 321-326. [CrossRef]

78. Wang, J.; Polsky, R.; Tian, B.; Chatrathi, M.P. Voltammetry on microfluidic chip platforms. Anal. Chem. 2000, 72, 5285-5289. [CrossRef] [PubMed]

79. El-Said, W.A.; Yea, C.H.; Kim, H.; Oh, B.K.; Choi, J.W. Cell-based chip for the detection of anticancer effect on HeLa cells using cyclic voltammetry. Biosens. Bioelectron 2009, 24, 1259-1265. [CrossRef] [PubMed]

80. Jang, A.; Zou, Z.; Lee, K.K.; Ahn, C.H.; Bishop, P.L. Potentiometric and voltammetric polymer lab chip sensors for determination of nitrate, $\mathrm{pH}$ and $\mathrm{Cd}(\mathrm{II})$ in water. Talanta 2010, 83, 1-8. [CrossRef]

81. Kokkinos, C.; Economou, A.; Raptis, I. Microfabricated disposable lab-on-a-chip sensors with integrated bismuth microelectrode arrays for voltammetric determination of trace metals. Anal. Chim. Acta 2012, 710, 1-8. [CrossRef] [PubMed]

82. Herzog, G.; Moujahid, W.; Twomey, K.; Lyons, C.; Ogurtsov, V.I. On-chip electrochemical microsystems for measurements of copper and conductivity in artificial seawater. Talanta 2013, 116, 26-32. [CrossRef]

83. Kokkinos, C.; Economou, A. Tin film sensor with on-chip three-electrode configuration for voltammetric determination of trace $\mathrm{Tl}(\mathrm{I})$ in strong acidic media. Talanta 2014, 125, 215-220. [CrossRef]

84. Shao, H.; Yu, H.; Li, X.; Li, Y.; Jiang, J.; Wei, H.; Wang, G.; Dai, T.; Chen, Q.; Yang, J.; et al. On-chip microwave signal generation based on a silicon microring modulator. Opt. Lett. 2015, 40, 3360-3363. [CrossRef]

85. Compton, R.G.; Coles, B.A.; Marken, F. Microwave activation of electrochemical processes at microelectrodes. Chem. Commun. 1988, 23, 2595-2596. [CrossRef] 
86. Tributsch, H.; Schlichthörl, G.; Elstner, L. Microwave (photo) electrochemistry: New insight into illuminated interfaces. Electrochim. Acta 1993, 38, 141-152. [CrossRef]

87. Tributsch, H. Microwave (photo)electrochemistry. Mod. Aspects Electrochem. 1998, 33, 435-522.

88. Rassaei, L.; Compton, R.G.; Marken, F. Microwave-enhanced electrochemistry in locally superheated aqueous-glycerol electrolyte media. J. Phys. Chem. C 2009, 113, 3046-3049. [CrossRef]

89. Ghanem, M.A.; Marken, F.; Coles, B.; Compton, R.G. Microwave-enhanced electrochemical processes in micellar surfactant media. J. Solid State Electrochem. 2005, 9, 809-815. [CrossRef]

90. Rassaei, L.; Nebel, M.; Rees, N.V.; Compton, R.G.; Schuhmann, W.; Marken, F. Discharge cavitation during microwave electrochemistry at micrometre-sized electrodes. Chem. Commun. 2010, 46, 812-814. [CrossRef] [PubMed]

91. O'Hara, J.A.; Khan, N.; Hou, H.; Wilmo, C.M.; Demidenko, E.; Dunn, J.F.; Swartz, H.M. Comparison of EPR oximetry and Eppendorf polarographic electrode assessments of rat brain $\mathrm{PtO}_{2}$. Physiol. Meas. 2004, 25, 1413-1423. [CrossRef]

92. Piette, L.H.; Ludwig, P.; Adams, R.N. Electron paramagnetic resonance and electrochemistry studies of electrochemically generated radical ions in aqueous solution. Anal. Chem. 1962, 34, 916-921. [CrossRef]

93. Fernando, K.R.; McQuillan, A.J.; Peake, B.M.; Wells, J. Cell for combined electrochemistry and ESR measurements at variable temperatures in a Varian TE 102 microwave cavity. J. Magn. Res. 1986, 68, 551-555.

94. Ghanem, M.A.; Thompson, M.; Compton, R.G.; Coles, B.A.; Harvey, S.; Parker, K.H.; O’Hare, D.; Marken, F. Microwave induced jet boiling investigated via voltammetry at ring-disk microelectrodes. J. Phys. Chem. B 2006, 110, 17589-17594. [CrossRef]

95. Ghanem, M.A.; Compton, R.G.; Coles, B.A.; Canals, A.; Marken, F. Microwave enhanced electroanalysis of formulations: Processes in micellar media at glassy carbon and at platinum electrodes. Analyst 2005, 130, 1425-1431. [CrossRef]

96. Rassaei, L.; French, R.W.; Compton, R.G.; Marken, F. Microwave-enhanced electroanalytical processes: Generator-collector voltammetry at paired gold electrode junctions. Analyst 2009, 134, 887-892. [CrossRef]

97. Pan, J.; Chen, Z.; Yao, M.; Li, X.; Li, Y.; Sun, D.; Yu, Y. A two-electrode system-based electrochemiluminescence detection for microfluidic capillary electrophoresis and its application in pharmaceutical analysis. Luminescence 2014, 29, 427-432. [CrossRef]

98. Förster, S.; Matysik, F.M.; Ghanem, M.A.; Marken, F. Capillary electrophoresis with microwave-enhanced electrochemical detection. Analyst 2006, 131, 1210-1212. [CrossRef] [PubMed]

99. Chandrasekhar, R.; Mapps, D.J. Properties of CoCrTa perpendicular films prepared by sputtering on platinum underlayer with different bias conditions. J. Magn. Magn. Mater. 1996, 155, 206-208. [CrossRef]

100. Attard, G.A.; Price, R. Electrochemical investigation of a structure sensitive growth mode: Palladium deposition on $\mathrm{Pt}(100)-$ hex-R0.7 ${ }^{\circ}$ and $\mathrm{Pt}(100)-(1 \times 1)$. Surf. Sci. 1995, 335, 63-74. [CrossRef]

101. Danilov, A.I.; Molodkina, E.B.; Rudnev, A.V.; Polukarov, Y.M.; Feliu, J.M. Kinetics of copper deposition on $\mathrm{Pt}(111)$ and $\mathrm{Au}(111)$ electrodes in solutions of different acidities. Electrochim. Acta 2005, 50, 5032-5043. [CrossRef]

102. Ho, W.H.; Liu, H.C.; Chen, H.C.; Yen, S.K. Characterization of electrolytic tin dioxide deposition on Pt for lithium ion battery applications. Surf. Coat. Technol. 2007, 201, 7100-7106. [CrossRef]

103. Bhaskaran, M.; Sriram, S.; Holland, A.S. RF magnetron sputtered perovskite-oriented PSZT thin films on gold for piezoelectric and ferroelectric transducers. Electron. Lett. 2006, 42, 244-245. [CrossRef]

104. Cao, Q.; Yang, S.; Gao, Q.; Lei, L.; Yu, Y.; Shao, J.; Liu, Y. Fast and controllable crystallization of perovskite films by microwave irradiation process. ACS Appl. Mater. Interfaces 2016, 8, 7854-7861. [CrossRef]

105. Ramasamy, P.; Lim, D.H.; Kim, B.; Lee, S.H.; Lee, M.S.; Lee, J.S. All-inorganic cesium lead halide perovskite nanocrystals for photodetector applications. Chem. Commun. 2016, 52, 2067-2070. [CrossRef]

106. Deng, H.; Yang, X.; Dong, D.; Li, B.; Yang, D.; Yuan, S.; Qiao, K.; Cheng, Y.B.; Tang, J.; Song, H. Flexible and semitransparent organolead triiodide perovskite network photodetector arrays with high stability. Nano Lett. 2015, 15, 7963-7969. [CrossRef]

107. Lee, Y.; Kwon, J.; Hwang, E.; Ra, C.H.; Yoo, W.J.; Ahn, J.H.; Park, J.H.; Cho, J.H. High-performance perovskite-graphene hybrid photodetector. Adv. Mater. 2015, 27, 41-46. [CrossRef]

108. Su, L.; Zhao, Z.X.; Li, H.Y.; Yuan, J.; Wang, Z.L.; Cao, G.Z.; Zhu, G. High-performance organolead halide perovskite-based self-powered triboelectric photodetector. ACS Nano 2015, 9, 11310-11316. [CrossRef] [PubMed] 
109. Lantto, V.; Saukko, S.; Toan, N.N.; Reyes, L.F.; Granqvist, C.G. Gas sensing with perovskite-like oxides having $\mathrm{ABO}_{3}$ and $\mathrm{BO}_{3}$ structures. J. Electroceram. 2004, 13, 721-726. [CrossRef]

110. Fergus, J.W. Perovskite oxides for semiconductor-based gas sensors. Sens. Actuators B 2007, 123, 1169-1179. [CrossRef]

111. Chaudhari, G.N.; Jagtap, S.V.; Gedam, N.N.; Pawar, M.J.; Sangawar, V.S. Sol-gel synthesized semiconducting $\mathrm{LaCo}_{0.8} \mathrm{Fe}_{0.2} \mathrm{O}_{3}$-based powder for thick film $\mathrm{NH}_{3}$ gas sensor. Talanta 2009, 78, 1136-1140. [CrossRef] [PubMed]

112. Kersen, U. Microstructural and surface characterization of solid state sensor based on $\mathrm{LaFeO}_{3}$-sigma oxide for detection of $\mathrm{NO}_{2}$. Analyst 2001, 126, 1377-1381. [CrossRef] [PubMed]

113. Wang, Y.Z.; Zhong, H.; Li, X.M.; Jia, F.F.; Shi, Y.X.; Zhang, W.G.; Cheng, Z.P.; Zhang, L.L.; Wang, J.K. Perovskite $\mathrm{LaTiO}_{3}-\mathrm{Ag}_{0.2}$ nanomaterials for nonenzymatic glucose sensor with high performance. Biosens. Bioelectron. 2013, 48, 56-60. [CrossRef]

114. Ye, D.; Xu, Y.; Luo, L.; Ding, Y.; Wang, Y.; Liu, X.; Xing, L.; Peng, J. A novel nonenzymatic hydrogen peroxide sensor based on $\mathrm{LaNi}_{0.5} \mathrm{Ti}_{0.5} \mathrm{O}_{3} / \mathrm{CoFe}_{2} \mathrm{O}_{4}$ modified electrode. Colloids Surf. B 2012, 89, 10-14. [CrossRef]

115. Hensinger, WK. Quantum information: Microwave ion-trap quantum computing. Nature 2011, 476, $155-156$. [CrossRef]

116. Ospelkaus, C.; Warring, U.; Colombe, Y.; Brown, K.R.; Amini, J.M.; Leibfried, D.; Wineland, D.J. Microwave quantum logic gates for trapped ions. Nature 2011, 476, 181-184. [CrossRef]

117. Timoney, N.; Baumgart, I.; Johanning, M.; Varón, A.F.; Plenio, M.B.; Retzker, A.; Wunderlich, C. Quantum gates and memory using microwave-dressed states. Nature 2011, 476, 185-188. [CrossRef]

118. Webster, S.C.; Weidt, S.; Lake, K.; McLoughlin, J.J.; Hensinger, W.K. Simple manipulation of a microwave dressed-state ion qubit. Phys. Rev. Lett. 2013, 111, 140501. [CrossRef] [PubMed]

119. Hoppensteadt, F. Spin torque oscillator neuroanalog of von Neumann's microwave computer. Biosystems 2015, 136, 99-104. [CrossRef] [PubMed]

120. Caloz, C.; Gupta, S.; Zhang, Q.; Nikfal, B. Analog signal processing: A possible alternative or complement to dominantly digital radio schemes. IEEE Microw. Mag. 2013, 14, 87-103. [CrossRef]

121. Nikfal, B.; Badiere, D.; Repeta, M.; Deforge, B.; Gupta, S.; Caloz, C. Distortion-less real-time spectrum sniffing based on a stepped group-delay phaser. IEEE Microw. Wirel. Compon. Lett. 2012, 22, 601-603. [CrossRef]

122. Abielmona, S.; Gupta, S.; Caloz, C. Compressive receiver using a CRLH-based dispersive delay line for analog signal processing. IEEE Trans. Microw. Theory Tech. 2009, 57, 2617-2626. [CrossRef]

123. Nikfal, B.; Gupta, S.; Caloz, C. Increased group-delay slope loop system for enhanced-resolution analog signal processing. IEEE Trans. Microw. Theory Tech. 2011, 59, 1622-1628. [CrossRef]

124. Gupta, S.; Abielmona, S.; Caloz, C. Microwave analog real-time spectrum analyzer (RTSA) based on the spectral-spatial decomposition property of leaky-wave structures. IEEE Trans. Microw. Theory Tech. 2009, 57, 2989-2999. [CrossRef]

125. Rambidi, N.G.; Shamayaev, K.E.; Peshkov, G.Y. Information processing using light sensitive chemical waves. Phys. Lett. A 2002, 298, 375-382. [CrossRef]

126. Vishnevskii, A.L.; Savchenko, V.I. Self-oscillations in the rate of CO oxidation on Pt (110). React. Kinet. Catal. Lett. 1989, 38, 167-173. [CrossRef]

127. Elokhin, V.I.; Matveev, A.V.; Gorodetskii, V.V. Self-oscillations and chemical waves in CO oxidation on Pt and Pd: Kinetic Monte Carlo models. Kinet. Catal. 2009, 50, 40-47. [CrossRef]

128. Imbihl, R.; Cox, M.P.; Ertl, G. Kinetic oscillations in the catalytic CO oxidation on Pt (100): Experiments. J. Chem. Phys. 1986, 84, 3519-3534. [CrossRef]

129. Trayer, V.V.; Elizarov, A.B. Electrochemical Integrating and Analog Storage Elements; Energiya Publ.: Moscow, USSR, 1971; p. 96. (In Russian)

130. Borovkov, V.S.; Grafov, B.M.; Novikov, A.A.; Novitsky, M.A.; Sokolov, L.A. Electrochemical Converters of the Primary Information; Mashinostroenie Publ.: Moscow, USSR, 1969; p. 196. (In Russian)

131. Voronkov, G.Y.; Gurevich, M.A.; Fedorin, V.A. Chemotronic Devices; VNIIEM Publ.: Moscow, USSR, 1965; p. 166. (In Russian)

132. Yushina, L.D. Solid State Chemotronics; IHTE UB RAS Publ.: Yekaterinburg, Russia, 2003; p. 204. (In Russian)

133. Strizhevsky, I.V.; Dmitriev, V.I.; Finlelshtein, E.B. Chemotronics; Nauka Publ.: Moscow, USSR, $1974 ;$ p. 191. (In Russian)

134. Khazaryan, E.V.; Runich, I.A. Chemotronics; Znanie Publ.: Moscow, USSR, 1978; p. 64. (In Russian) 
135. Lapides, L.M. Chemotronics; Voenizdat Publ.: Moscow, USSR, 1968; p. 128. (In Russian)

136. Frumkin, A.; Obrutschewa, A. Adsorption of electrolytes on platinum black. Z. Anorg. Allg. Chem. 1926, 158, 84. [CrossRef]

137. Frumkin, A.; Donde, A. Adsoption of Electrolytes on Platinum Black and Carbon. Ber. Dt. Chem. Ges. A 1927, 2, 1816. [CrossRef]

138. Frumkin, A.N.; Shlygin, A.I. About the Platinum Electrode. Dok. Akad. Nauk SSSR 1934, 2, $173-179$. (In Russian)

139. Frumkin, A.; Petry, O.; Marvet, R. The dependence of the double layer charge on the platinum hydrogen electrode surface upon the potential. J. Electroanal. Chem. 1966, 12, 504. [CrossRef]

140. Frumkin, A.N.; Nekrasov, L.N. On the ring-disk electrode. Dok. Akad. Nauk SSSR 1959, 126, 115.

141. Ivanov-Shits, A.K.; Demyanets, L.N. Solid State Ionics Materials. Priroda 2003, 12, 35-43. (In Russian)

142. Zhao, Y.; Daemen, L.L. Superionic conductivity in lithium-rich anti-perovskites. J. Am. Chem. Soc. 2012, 134, 15042-15047. [CrossRef]

143. Deng, Z.; Radhakrishnan, B.; Ong, S.P. Rational composition optimization of the lithium-rich $\mathrm{Li}_{3} \mathrm{OCl}_{1-\mathrm{x}} \mathrm{Br}_{\mathrm{x}}$ anti-perovskite superionic conductors. Chem. Mater. 2015, 27, 3749-3755. [CrossRef]

144. Lu, Z.; Chen, C.; Baiyee, Z.M.; Chen, X.; Niu, C.; Ciucci, F. Defect chemistry and lithium transport in $\mathrm{Li}_{3} \mathrm{OCl}$ anti-perovskite superionic conductors. Phys. Chem. Chem. Phys. 2015, 17, 32547-32555. [CrossRef]

145. Sinha, M.M.; Wakamura, K. Study of phonons and normal mode analysis of perovskite-type superionic conductors. Solid State Ionics 2000, 136, 1345-1350. [CrossRef]

146. Bannikov, V.V.; Ivanovskii, A.L. Elastic and electronic properties of antiperovskite-type Pd- and Pt-based ternary carbides from first-principles calculations. J. Alloys Compd. 2013, 577, 615-621. [CrossRef]

147. Ham, D.J.; Lee, J.S. Transition metal carbides and nitrides as electrode materials for low temperature fuel cells. Energies 2009, 2, 873-899. [CrossRef]

148. Vallance, S. Microwave Synthesis and Mechanistic Examination of the Transition Metal Carbides. Ph.D. Thesis, University of Nottingham, Nottingham, UK, 2008.

149. Essaki, K.; Rees, E.J.; Buestein, G.T. Synthesis of nanoparticulate tungsten carbide under microwave irradiation. J. Amer. Ceram. Soc. 2010, 93, 692-695. [CrossRef]

150. Ivanovskii, A.L. Platinum-based and platinum-doped layered superconducting materials: Synthesis, properties and simulation. Experimental and theoretical results for newest group of high-temperature superconductors. Platin. Metals Rev. 2013, 57, 87-100. [CrossRef]

151. Lidorenko, N.S.; Fish, M.L. Application of chemotronic transducers in measurement techniques. Meas. Tech. 1967, 10, 772-777. [CrossRef]

152. Evangelakis, G.A.; Miliotis, D. Ionic and superionic conductivities of $\mathrm{SrF}_{2}$ crystals in a wide frequency range. Phys. Rev. B 1987, 36, 4958-4961. [CrossRef]

153. Grachev, G.N.; Medvedev, A.E. Acceleration of the laser plasma ions in a microwave resonator. In Proceedings of the XXXVII International Conference on the Physics of Plasma and Controlled Thermonuclear Fusion, Zvenigorod, Russia, 12 February 2010.

154. Bratman, V.; Denisov, G.; Ginzburg, N.; Petelin, M.L. FEL's with Bragg reflection resonators: Cyclotron autoresonance masers versus ubitrons. IEEE J. Quantum Electron. 1983, 19, 282-296. [CrossRef]

155. Skaggs, L.S.; Nygard, J.C.; Lanzl, L.H. Design and initial operation of a 50-Mev microwave linear accelerator for electron beam therapy. Radiology 1955, 64, 117. [CrossRef]

156. Halpern, J.; Everhart, E.; Rapuano, R.A.; Slater, J.C. Preliminary studies on the design of a microwave linear accelerator. Phys. Rev. 1946, 69, 688.

157. Houck, T.; Deadrick, F.; Giordano, G.; Henestroza, E.; Lidia, S.; Reginato, L.; Vanecek, D.; Westenskov, G.A.; $\mathrm{Yu}, \mathrm{S}$. Prototype microwave source for a relativistic klystron two-beam accelerator. IEEE Trans. Plasma Sci. 1996, 24, 938-946. [CrossRef]

158. Shintake, T.; Huke, K.; Tanaka, J.; Sato, I.; Kumabe, I. Development of microwave undulator. Jpn. J. Appl. Phys. 1983, 22, 844. [CrossRef]

159. Barberis, L.; Icardi, M.; Portesine, M.; Tenconi, S.; Di Marco, P.G.; Martelli, A.; Fouchi, P.G. On the use of a microwave linear accelerator for control of carrier lifetime in electronic silicon devices. Radiat. Phys. Chem. 1985, 26, 165-172. [CrossRef]

160. Shpitalnik, R.; Cohen, C.; Dothan, F.; Friedland, L. Autoresonance microwave accelerator. J. Appl. Phys. 1991, 70, 1101-1106. [CrossRef] 
161. Shpitalnik, R. Stability analysis, finite current effects, and experimental results in the autoresonance microwave accelerator. J. Appl. Phys. 1992, 71, 1583-1587. [CrossRef]

162. Hirshfield, J.L.; LaPointe, M.A.; Ganguly, A.K.; Yoder, R.B.; Wang, C. Multimegawatt cyclotron autoresonance accelerator. Phys. Plasmas 1996, 3, 2163-2168. [CrossRef]

163. Goren, Y.; Sessler, A.M. Phase control of the microwave radiation in free electron laser two-beam accelerator. In Proceedings of the Orsay Workshop on New Developments in Particle Acceleration Techniques; CERN: Orsay, France, 1987; p. 20.

164. Zhang, T.B.; Marshall, T.C. Microwave inverse free-electron-laser accelerator using a small "phase window". Phys. Rev. E 1994, 50, 1491-1495. [CrossRef]

165. Zhang, T.B.; Marshall, T.C.; LaPointe, M.A.; Hirshfield, J.L.; Ron, A. Microwave inverse Cerenkov accelerator. Phys. Rev. E 1996, 54, 1918. [CrossRef]

166. Kim, S.W.; Schneider, R.J.; von Reden, K.F.; Hayes, J.M.; Wills, J.S.C. Test of negative ion beams from a microwave ion source with a charge exchange canal for accelerator mass spectrometry applications. Rev. Sci. Instrum. 2002, 73, 846-848. [CrossRef]

167. Pankratov, S.K.; Gradov, O.V. Computer classifier and database for the selection of the accelerator mass-spectrometry tools foe geoarcheological and archeomineralogical studies. In Geoarcheology and Archeological Mineralogy -2015; Institute of Mineralogy UB RAS: Miass, Russia, 2015; pp. 41-44. (In Russian)

168. Urbanus, W.H.; Bannenberg, J.G.; Doorn, S.; Douma, S.; Ishikawa, J.; Saris, F.W.; Koudis, R.; Dubbelman, P. A microwave ion source and injector system for a Van de Graaff accelerator. Nucl. Instrum. Methods Phys. Res. Sect. A Accel. Spectrom. Detect. Assoc. Equip. 1988, 267, 237-241. [CrossRef]

169. Zaitsev, N.I.; Ilyakov, E.V.; Korablev, G.S. A high-current microsecond thermionic-cathode electron accelerator for powerful microwave devices. Instrum. Exp. Tech. 1995, 38, 380-385.

170. Hull, A.W. The dispenser cathode. A new type of thermionic cathode for gaseous discharge tubes. Phys. Rev. 1939, 56, 86. [CrossRef]

171. Tuck, R.A. Thermionic cathode surfaces: The state-of-the-art and outstanding problems. Vacuum 1983, 33, 715-721. [CrossRef]

172. Levi, R. Improved "Impregnated Cathode". J. Appl. Phys. 1955, 26, 639. [CrossRef]

173. Chen, P.K.; Rosana, M.R.; Dudley, G.B.; Stiegman, A.E. Parameters affecting the microwave-specific acceleration of a chemical reaction. J. Org. Chem. 2014, 79, 7425-7436. [CrossRef]

174. Sasaki, S.; Ishibashi, N.; Kuwamura, T.; Sano, H.; Matoba, M.; Nisikawa, T.; Maeda, M. Excellent acceleration of the Diels-Alder reaction by microwave irradiation for the synthesis of new fluorine-substituted ligands of NMDA receptor. Bioorg. Med. Chem. Lett. 1998, 8, 2983-2986. [CrossRef]

175. Rosana, M.R.; Hunt, J.; Ferrari, A.; Southworth, T.A.; Tao, Y.; Stiegman, A.E.; Dudley, G.B. Microwave-specific acceleration of a Friedel-Crafts reaction: Evidence for selective heating in homogeneous solution. J. Org. Chem. 2014, 79, 7437-7450. [CrossRef]

176. Seipel, K.R.; Platt, Z.H.; Nguyen, M.; Holland, A.W. Microwave-assisted synthesis of phenylene-bridged aminophosphine ligands: Acceleration of $\mathrm{N}$-arylation and aryl fluoride phosphorylation reactions. J. Org. Chem. 2008, 73, 4291-4294. [CrossRef]

177. Hou, C.; Chen, Y.; Li, W. Thiocarbamide and microwave-accelerated green methylation of cassava starch with dimethyl carbonate. Carbohydr. Res. 2012, 355, 87-91. [CrossRef]

178. Shieh, W.C.; Dell, S.; Repic, O. 1,8-Diazabicyclo[5.4.0]undec-7-ene (DBU) and microwave-accelerated green chemistry in methylation of phenols, indoles, and benzimidazoles with dimethyl carbonate. Org. Lett. 2001, 3, 4279-4281. [CrossRef]

179. Mayo, K.G.; Nearhoof, E.H.; Kiddle, J.J. Microwave-accelerated ruthenium-catalyzed olefin metathesis. Org. Lett. 2002, 4, 1567-1570. [CrossRef] [PubMed]

180. Wipf, P.; Janjic, J.; Stephenson, C.R. Microwave-assisted synthesis of allylic amines: Considerable rate acceleration in the hydrozirconation-transmetalation-aldimine addition sequence. Org. Biomol. Chem. 2004, 2, 443-445. [CrossRef] [PubMed]

181. Géci, I.; Filichev, V.V.; Pedersen, E.B. Stabilization of parallel triplexes by twisted intercalating nucleic acids (TINAs) incorporating 1,2,3-triazole units and prepared by microwave-accelerated click chemistry. Chemistry 2007, 13, 6379-6386. [CrossRef] [PubMed]

182. Schmidt, B.; Riemer, M.; Karras, M. 2,2'-Biphenols via protecting group-free thermal or microwave-accelerated Suzuki-Miyaura coupling in water. J. Org. Chem. 2013, 78, 8680-8688. [CrossRef] 
183. Schmidt, A.F.; Kurokhtina, A.A.; Svechkarev, A.N.; Smirnov, V.V.; Al-Halaiqa, A. Problems of distinguishing the homogeneous and heterogeneous mechanisms of the Suzuki reaction. Kinet. Catal. 2010, 51, 113-118. [CrossRef]

184. Schmidt, A.F.; Al-Halaiqa, A.; Smirnov, V.V. New approaches to Heck reaction testing for homogeneity-heterogeneity. Kinet. Catal. 2008, 49, 395-400. [CrossRef]

185. Schmidt, A.F.; Al-Halaiqa, A.; Smirnov, V.V.; Kurokhtina, A.A. State of palladium in ligandless catalytic systems for the Heck reaction of nonactivated bromobenzene. Kinet. Catal. 2008, 49, 638-643. [CrossRef]

186. Horikoshi, S.; Serpone, N. Role of microwaves in heterogeneous catalytic systems. Catal. Sci. Technol. 2014, 4, 1197-1210. [CrossRef]

187. Zhou, J.; Xu, W.; You, Z.; Wang, Z.; Luo, Y.; Gao, L.; Yin, C.; Peng, R.; Lan, L. A new type of power energy for accelerating chemical reactions: The nature of a microwave-driving force for accelerating chemical reactions. Sci. Rep. 2016, 6, 25149. [CrossRef]

188. Dudley, G.B.; Richert, R.; Stiegman, A.E. On the existence of and mechanism for microwave-specific reaction rate enhancement. Chem. Sci. 2015, 6, 2144-2152. [CrossRef]

189. Nuechter, M.; Mueller, U.; Ondruschka, B.; Tied, A.; Lautenschlaeger, W. Microwave-assisted chemical reactions. Chem. Eng. Technol. 2003, 26, 1207-1216. [CrossRef]

190. Horikoshi, S.; Serpone, N. Microwaves in Catalysis: Methodology and Applications; John Wiley \& Sons: Weinheim, Germany, 2015; 454p.

191. Kokel, A.; Schäfer, C.; Török, B. Application of microwave-assisted heterogeneous catalysis in sustainable synthesis design. Green Chem. 2017, 19, 3729-3751. [CrossRef]

192. Cha Chang, Y. Process and Reactor for Char-Gas Oxide Reactions by Radiofrequency Catalysis. U.S. Patent 5,269,892, 14 December 1993.

193. Cha Chang, Y. Process and Reactor for Char-Gas Oxide Reactions by Radiofrequency Catalysis. U.S. Patent 5,362,451, 8 November 1994.

194. Cha Chang, Y. Process for Selected Gas Oxide Removal by Radiofrequency Catalysts. U.S. Patent 5,246,554. 21, 21 September 1993.

195. Cha Chang, Y. Process for Oxide Reactions by Radiofrequency-Char Catalysis. U.S. Patent 5,256,265, 26 October 1993.

196. Buchachenko, A.L.; Frankevich, E.L. Chemical Generation and Reception of Radio and Microwaves; VCH Publishers: New York, NY, USA, 1994; p. 180.

197. Buchachenko, A.L.; Berdinskii, V.L. Chemically induced radio-frequency emission and chemical radiophysics. Russ. Chem. Rev. 1983, 52,1-12. [CrossRef]

198. Berdinskii, V.L.; Buchachenko, A.L.; Pershin, A.D. Theoretical analysis of a radio-frequency maser with chemical pumping of the nuclear Zeeman energy levels. Theor. Exp. Chem. 1977, 12, 519-524. [CrossRef]

199. Zhuravlev, A.G.; Berdinskii, V.L.; Buchachenko, A.L. Generation of high-frequency current by the products of a photochemical reaction. JETP Lett. 1978, 28, 140-142.

200. Berdinsky, V.L.; Yasina, L.L.; Buchachenko, A.L. Microwave Magnetic Isotope Effect. Theory. Khimicheskaya Fizika 2005, 24, 35-42. (In Russian)

201. Buchachenko, A.L.; Berdinsky, V.L. Electron spin catalysis. Chem. Rev. 2002, 102, 603-612. [CrossRef]

202. Buchachenko, A.L. Spin Chemistry. Khimiya i Zhizn 2005, 3, 8-13. (In Russian)

203. Minaev, B.F.; Agren, H. Spin uncoupling in ethylene activation by palladium and platinum atoms. Int. J. Quantum Chem. 1999, 72, 581-596. [CrossRef]

204. Minaev, B.F.; Agren, H. Spin uncoupling in molecular hydrogen activation by platinum clusters. J. Mol. Catal. A 1999, 149, 179-195. [CrossRef]

205. Lindgren, M.; Minaev, B.; Glimsdal, E.; Vestberg, R.; Westlund, R.; Malmstrom, E. Electronic states and phosphorescence of dendron functionalized platinum(II) acetylides. J. Lumin. 2007, 124, 302-310. [CrossRef]

206. Minaev, B.; Jansson, E.; Lindgren, M. Application of density functional theory for studies of excited states and phosphorescence of platinum(II) acetylides. J. Chem. Phys. 2006, 125, 094306. [CrossRef] [PubMed]

207. Glimsdal, E.; Carlsson, M.; Eliasson, B.; Minaev, B.; Lindgren, M. Excited states and two-photon absorption of some novel thiophenyl Pt (II)-ethynyl derivatives. J. Phys. Chem. A 2007, 111, 244-250. [CrossRef] [PubMed]

208. Minaev, B.F. Ab initio study of the PtC molecule. A new assignment of the red bands to the $1^{3} \Pi_{\Omega}\left(\Omega=1,0^{+}\right)-X$ ${ }^{1} \Sigma^{+}$transitions. Phys. Chem. Chem. Phys. 2000, 2, 2851-2856. [CrossRef] 
209. Shishkina, S.N.; Galagan, R.L.; Minaev, B.F. Synthesis of nanostructured polymetallic composites based on palladium and quantum-chemical simulation of initial stages of the process. Russ. J. Appl. Chem. 2012, 85, 564-574. [CrossRef]

210. Minaev, B.F. The role of triplet excited state of hydrocarbons in catalysis by transition-metal species. Bull. Pol. Acad. Sci. Chem. 2001, 49, 27-56.

211. Mohammed, A.; Minaev, B.; Agren, H.; Lindgren, M.; Norman, P. Classification of Raman active modes of platinum(II) acetylides: A combined experimental and theoretical study. Chem. Phys. Lett. 2009, 481, 209-213. [CrossRef]

212. Gradov, O.V.; Gradova, M.A. Multifactor response of the dispersed soft matter precursors under microwave-induced self-organization. Phys. A. SPb-2015. Sect. Dev. Mater. THz Microw. Ranges 2015, 394. [CrossRef]

213. Chen, Y.; Fan, X.; Xie, Y.; Zhou, Y.; Wang, T.; Wilson, J.D.; Simons, R.N.; Chui, S.-T.; Xiao, J.Q. Tunable magnetic resonance in microwave spintronics devices. IEEE MTT-S Int. Microw. Symp. (IMS) 2015, 1-4. [CrossRef]

214. Parkes, D.E.; Shelford, L.R.; Wadley, P.; Holy, V.; Wang, M.; Hindmarch, A.T.; van der Laan, G.; Campion, R.P.; Edmonds, K.W.; Cavill, S.A.; et al. Magnetostrictive thin films for microwave spintronics. Sci. Rep. 2013, 3, 2220. [CrossRef]

215. Microwave Spintronics as an Alternative Path to Components and Systems for Telecommunications; Storage and Security Applications (FP-7-ICT-2011-85). Available online: http://cordis.europa.eu/project/rcn/106473_ en.html (accessed on 30 August 2019).

216. Scientific Report of the Laboratory of Physics of Magnetic Heterostructures and Spintronics for Energy-Storage Informational Technologies (Moscow Institute of Physics and Technology). 2014. Available online: https://mipt.ru/upload/medialibrary/648/МфТИ_в_2014_году.pdf (accessed on 30 August 2019).

217. Shlimak, I.; Vagner, I.D. Isotopically Engineered Si as a Promising Material for Spintronics and Semiconductor-Based Nuclear Spin Quantum Computers. NATO Sci. Ser. 2003, 106, 281-287.

218. Morton, J.J. Quantum Spintronics Using Donors in Isotopically Engineered Silicon. Project \# EP/H025952/2. Available online: http://gow.epsrc.ac.uk/NGBOViewGrant.aspx?GrantRef=EP/H025952/2 (accessed on 30 August 2019).

219. Tokoro, H.; Ohkoshi, S. Novel magnetic functionalities of Prussian blue analogs. Dalton Trans. 2011, 40, 6825-6833. [CrossRef] [PubMed]

220. Ohkoshi, S.I.; Nakagawa, K.; Tomono, K.; Imoto, K.; Tsunobuchi, Y.; Tokoro, H. High proton conductivity in Prussian blue analogues and the interference effect by magnetic ordering. J. Am. Chem. Soc. 2010, 132, 6620-6621. [CrossRef] [PubMed]

221. Mizuguchi, M. Development of Nano Spin-Ionics. Project No.: FY 2014-2016 [Grant-in-Aid for Challenging Exploratory Research]. Available online: http://magmatelab.imr.tohoku.ac.jp/ProjectEng.html (accessed on 30 August 2019).

222. Danilin, V.N.; Kushnirenko, A.I.; Petrov, G.V. Analog Semiconductor Microwave Integrated Circuits; Radio I Sviaz Publ.: Moscow, USSR, 1985; p. 192. (In Russian)

223. Arofeev, V.I.; Privalov, V.N.; Yashin, A.A. Matching Devices for Hybrid and Semiconductor Microwave Integrated Circuits; Naukova Dumka Publ.: Kiev, USSR, 1989; p. 192. (In Russian)

224. Gvozdev, V.I.; Nefyodov, E.I. 3D-Microwave Integrated Circuits; Nauka Publ.: Moscow, USSR, 1985; p. 256. (In Russian)

225. Gradov, O.V.; Gradova, M.A. Autowave measurements in microwave-induced self-organization of structures. In Proceedings of the All-Russian Scientific and Technical Conference "Microwave Microelectronics", St. Petersburg, Russia, 4-12 June 2012; pp. 371-376. (In Russian).

226. Gradov, O.V. The use of angular descriptors and radiation patterns in high-frequency and microwave thermal analysis of anisotropic-heterogeneous structures on a chip. In Proceedings of the Conference on Thermal Analysis and Calorimetry (RTAC-2016), St. Petersburg, Russia, 19-23 September 2016. (In Russian).

227. Gradov, O.V. In situ tunable laser diode spectroscopy of the processes and products of the microwave-induced self-organization in the soft mater active media. In Proceedings of the 2-nd International Conference and Exhibition on Mesoscopic and Condensed Matter Physics, Chicago, IL, USA, 26-28 October 2016.

228. Církva, V.; Relich, S. Microwave photochemistry. Applications in organic synthesis. Mini-Rev. Org. Chem. 2011, 8, 282-293. [CrossRef] 
229. Gradov, O.V.; Gradova, M.A. Reaction-diffusion optoelectronics based on dispersed semiconductors. J. Phys. Conf. Ser. 2015, 643, 012072. [CrossRef]

230. Gradov, O.V.; Gradova, M.A. Microwave-induced self-organization in saturated solutions and colloidal suspensions of Fe(III) salts. In Proceedings of the IV International Conference "Supramolecular Systems at the Interface", Tuapse, Russia, 21-25 September 2015; p. 78. (In Russian).

231. Gradov, O.V.; Gradova, M.A. Microwave-induced self-organization in mineral systems. I. Prussian blue (2.45 GHz; 450 W; 3 min). In Pangaea [Dataset], Microwave-Induced Self-Organization in Mineral Systems; Alfred Wegener Institute, Helmholtz Center for Polar and Marine Research, Center for Marine Environmental Sciences, University of Bremen: Bremen, Germany, 2019.

232. Li, B.; Rowais, H.A.; Kosel, J. Surface acoustic wave based magnetic sensors. In Modeling and Measurement Methods for Acoustic Waves and for Acoustic Microdevices; Beghi, M.G., Ed.; InTech: Rijeka, Croatia, 2013; pp. 355-380.

233. Woodard, S.E.; Taylor, B.D.; Shams, O.A.; Fox, R.L. Magnetic field response measurement acquisition system. NASA Tech. Briefs 2006, 30, 28.

234. Rosensweig, R.E. Ferrohydrodynamics; Dover Publications: Mineola, NY, USA, 2013; p. 368.

235. Carugo, D.; Octon, T.; Messaoudi, W.; Fisher, A.L.; Carboni, M.; Harris, N.R.; Hill, M.; GlynneJones, P. A thin-reflector microfluidic resonator for continuous-flow concentration of microorganisms: A new approach to water quality analysis using acoustofluidics. Lab Chip 2014, 14, 3830-3842. [CrossRef]

236. Travagliati, M.; Shilton, R.J.; Pagliazzi, M.; Tonazzini, I.; Beltram, F.; Cecchini, M. Acoustofluidics and whole-blood manipulation in surface acoustic wave counterflow devices. Anal. Chem. 2014, 86, 10633-10638. [CrossRef]

237. Kochervinskii, V.V.; Malyshkina, I.A.; Gradova, M.A.; Kozlova, N.V.; Shmakova, N.A.; Buzin, M.I.; Korlyukov, A.A.; Bedin, S.A. On the features of cooperative mobility in the amorphous phase of ferroelectric polymers. Colloid Polym. Sci. 2019, 297, 513-520. [CrossRef]

238. Kochervinsky, V.V.; Kozlova, N.V.; Shmakova, N.A.; Kalabukhova, A.V.; Kiselev, D.A.; Malinkovich, M.D.; Gradova, M.A.; Gradov, O.V.; Bedin, S.A. The influence of dye molecules on the polarization process of a ferroelectric copolymer of vinylidene fluoride. Crystallogr. Rep. 2018, 63, 983-988. [CrossRef]

239. Kochervinskii, V.V.; Gradova, M.A.; Gradov, O.V.; Kiselev, D.A.; Ilina, T.S.; Kalabukhova, A.V.; Kozlova, N.V.; Shmakova, N.A.; Bedin, S.A. Structural, optical, and electrical properties of ferroelectric copolymer of vinylidenefluoride doped with rhodamine 6G dye. J. Appl. Phys. 2019, 125, 044103. [CrossRef]

240. Gradov, O.V. A novel principle for the design of CMOS-based labs-on-a-chip: Flexible configuration with non-solid walls controlled by the external field and multi-level signal conversion for measuring multiple parameters at a single chip. In Proceedings of the Conference "Actual Problems of Physical and Functional Electronics", Ulyanovsk, Russia, 1-3 December 2015. (In Russian).

241. Gradov, O.V.; Gradova, M.A. Soft matter reaction-diffusion and ferrofluid patterns as dynamic microchannels for optoelectronic lab-on-a-chip with the field-controlled geometry/topology. Comput. Nanotechnol. 2018, 4, 75-77.

(C) 2019 by the authors. Licensee MDPI, Basel, Switzerland. This article is an open access article distributed under the terms and conditions of the Creative Commons Attribution (CC BY) license (http://creativecommons.org/licenses/by/4.0/). 